\title{
Extreme sensitivity of gene expression in human SH-SY5Y neurocytes to ultra-low doses of Gelsemium sempervirens
}

\author{
Marta Marzotto ${ }^{1}$, Debora Olioso ${ }^{1}$, Maurizio Brizzi ${ }^{2}$, Paola Tononi ${ }^{3}$, Mirco Cristofoletti ${ }^{1}$ and Paolo Bellavite ${ }^{1 *}$
}

\begin{abstract}
Background: Gelsemium sempervirens L. (Gelsemium s.) is a traditional medicinal plant, employed as an anxiolytic at ultra-low doses and animal models recently confirmed this activity. However the mechanisms by which it might operate on the nervous system are largely unknown. This work investigates the gene expression of a human neurocyte cell line treated with increasing dilutions of Gelsemium s. extract.
\end{abstract}

Methods: Starting from the crude extract, six $100 \times$ (centesimal, c) dilutions of Gelsemium s. (2c, 3c, 4c, 5c, 9c and 30c) were prepared according to the French homeopathic pharmacopoeia. Human SH-SY5Y neuroblastoma cells were exposed for $24 \mathrm{~h}$ to test dilutions, and their transcriptome compared by microarray to that of cells treated with control vehicle solutions.

Results: Exposure to the Gelsemium s. 2c dilution (the highest dose employed, corresponding to a gelsemine concentration of $6.5 \times 10^{-9} \mathrm{M}$ ) significantly changed the expression of 56 genes, of which 49 were down-regulated and 7 were overexpressed. Several of the down-regulated genes belonged to G-protein coupled receptor signaling pathways, calcium homeostasis, inflammatory response and neuropeptide receptors. Fisher exact test, applied to the group of 49 genes down-regulated by Gelsemium s. 2c, showed that the direction of effects was significantly maintained across the treatment with high homeopathic dilutions, even though the size of the differences was distributed in a small range.

Conclusions: The study shows that Gelsemium s., a medicinal plant used in traditional remedies and homeopathy, modulates a series of genes involved in neuronal function. A small, but statistically significant, response was detected even to very low doses/high dilutions (up to 30c), indicating that the human neurocyte genome is extremely sensitive to this regulation.

\section{Background}

Gelsemium sempervirens (Gelsemium s.), also called yellow jasmine, is a plant belonging to the Loganiaceae family. All parts of the plant contain the major active principle gelsemine as well as other toxic strychninerelated alkaloids, such as gelseminine and sempervirine [1-3]. In the phytotherapy literature, Gelsemium s. has been reported to show sedative, analgesic and anti-seizure properties [4,5] while in the homeopathic Materia Medica and literature, Gelsemium s. is described as a remedy for a variety of anxiety-like psychological and behavioral

\footnotetext{
* Correspondence: paolo.bellavite@univr.it

${ }^{1}$ Department of Pathology and Diagnostics, University of Verona, Strada Le Grazie 8, Verona 37134, Italy

Full list of author information is available at the end of the article
}

symptoms [6-9]. The anxiolytic, antidepressant and/or analgesic action of Gelsemium s. extracts and its purified components has been recently demonstrated in animal models [10-16]. Other reports in the literature suggest this plant species may exhibit anticancer and immunemodulating activity [17-20].

The question of dosage is obviously central to pharmacology and of particular interest in homeopathic pharmacopoeia, where the procedure of serial dilutions followed by shaking has sparked much debate. The original extract (Mother Tincture, MT) is generally obtained by grinding the medicinal plant matter with a mortar and pestle and dissolving it in ethanolic solution. According to the most widely-used French pharmacopoeia, the first centesimal (1c) dilution is obtained by dissolving 
one volume of MT in 99 volumes of $30 \%$ ethanol in water and then subjecting it to vigorous shaking (succussion or "dynamization"). Subsequent c dilutions are prepared by repeating the same procedure. Although the lower dilutions (i.e., $2 \mathrm{c}$ to $5 \mathrm{c}$ ) contain substantial amount of the original active phytochemical substances, their concentration progressively decreases as the number of dilutions increases. Thus, in order to address possible mechanisms of action of high dilutions, physical or chemical mechanisms involving changes imparted to the solvent itself have been hypothesized [21-23]. This is a fairly controversial question in the literature on Gelsemium s., since most authors have investigated only a narrow range of doses or dilutions. It is also important, when dealing with elusive phenomena such as biological responses to diluted and dynamized substances, to take special care with the controls: the recent consensus recommendation among researchers in this field is for protocols that use the diluted and succussed vehicle solution as a control, however this is still a debated theme and has been done only in few cases [24,25].

Previous investigations in our laboratory [26,27] have shown a significant anxiolytic-like activity of Gelsemium $s$. high dilutions (namely 5c, 7c, 9c and 30c according to different test paradigms) in mice, using emotional response models. Other laboratories have also reported in vivo $[16,19,28,29]$ or in vitro [30] effects of Gelsemium $s$. in extremely low doses or high dilution/dynamization, but its action at the cellular level has not been fully clarified. To follow up the above evidence of an anxiolytic effect in animal models, we decided to investigate the Gelsemium s. mechanism of action in neuronal models by assessing the drug effects on whole genome expression changes. The SH-SY5Y and IMR-32 human neuroblastoma cells were used since are widely employed in neuropharmacology [31-33]. Finally, this approach allowed us to test several replications of multiple doses and dilutions of the remedy, taking advantage of high-throughput and easily reproducible microarray technology.

Cells were treated with a wide variety of doses: in total, we tested 6 increasing dilutions - which was the maximum sample size permitted by technical constraints - from the low dilution $2 \mathrm{c}$ (dilution factor $10^{4}$ ) to the extremely high dilution 30c (dilution factor $10^{60}$ ). The $5 \mathrm{c}, 9 \mathrm{c}, 30 \mathrm{c}$ dilutions are among the most frequently used drug formulations in complementary therapies on humans [34]. The drug effects were compared with those of the same solvent used for the dilutions of Gelsemium s., just without the plant extract (control solutions). After testing for possible toxic effects of any dilution on cell viability, their effectiveness in changing gene expression was evaluated using a microarray designed for the whole human transcriptome. Gelsemium s. 2c was checked in SH-SY5Y and IMR-32 cells and the most responsive cell line was chosen for testing also higher dilutions/dynamizations.

\section{Methods}

\section{Preparation of Gelsemium s. and control solutions}

The homeopathic dilutions/dynamizations were prepared in a manner comparable to methods used by commercial manufacturers, i.e. using 30\% ethanol for all dilution/ succussion steps. Since ethanol at higher concentration may be toxic for cells the $100 x$, last dilution/succussion was made in pure water. The detailed procedure was carefully repeated in all experiments and precisely reported below, since it is relevant as basic science research on homeopathic medicine progresses. Whole hydroalcoholic extract (MT) of Gelsemium s. was produced by Boiron Laboratoires, Lyon (F) according to the French Homeopathic Pharmacopoeia [35]. The gelsemine content in the MT was $6.5 \times 10^{-4} \mathrm{M}$. MT was diluted 100 times in $30 \%$ ethanol/distilled water to obtain the $1 c$ dilution. Subsequent serial $100 \times$ dilutions up to 29 c, each followed by vigorous succussion (shaking) were then prepared in the same solvent using glass bottles. $30-\mathrm{ml}$ bottles containing 1c, 2c, 3c, 4c, 8c and 29c dilutions were supplied by the manufacturer wrapped in aluminum foil and stored in the dark at room temperature in a metal cupboard. The control solutions (solvent) were prepared as the drug dilutions just without the plant extract. The $1 \mathrm{c}, 2 \mathrm{c}, 3 \mathrm{c}, 4 \mathrm{c}, 8 \mathrm{c}$ and 29 c solvent samples contain only $30 \%$ ethanol/distilled water, but differ for the number of succussions performed. To prepare the final dilutions used in the tests, immediately before the experiments, $0.05 \mathrm{ml}$ of the solutions (Gelsemium s. and controls) were added to $4.95 \mathrm{ml}$ of distilled sterile-filtered water (Sigma-Aldrich) in a sterile $15 \mathrm{ml}$ Falcon polystyrene plastic tube and shaken in a DinaA mechanical shaker for $7.5 \mathrm{sec}$ (150 strokes). This yielded the 2c, 3c, 4c, 5c, 9c and 30c succussed dilutions, with ethanol concentration lowered to $0.3 \%$ (v/v) (final $0.03 \%$ in the assay system).

UV-visible absorption spectra of Gelsemium s. samples were performed with a Jasco V550 double-beam spectrophotometer using quartz cuvettes with 1-cm optical path and control solutions as the reference samples.

\section{Exposure of cells to Gelsemium s. and control dilutions}

Human neuroblastoma cell line SH-SY5Y [36,37], kindly provided by prof. Ubaldo Armato (Department of Life and Reproduction Sciences, University of Verona), was grown in DMEM-F12 (1:1) medium (Lonza, Walkersville, MD, USA), supplemented with $10 \%$ foetal bovine serum (FBS; Lonza), penicillin (100 units $\mathrm{ml}^{-1}$ ) and streptomycin $\left(100 \mathrm{mg} \mathrm{ml}^{-1}\right.$ ) (Lonza). The culture medium was replaced every three days. The cells were grown in Greiner plastic culture flasks at $37^{\circ} \mathrm{C}$ in a $5 \% \mathrm{CO}_{2}$ atmosphere, until $80 \%$ confluence was reached. Cells were propagated after 
reactivation of cryogenates until the fourth culture passage and then used for the gene expression assay. Cells were counted in duplicate in a Thoma counting chamber after staining with Turk blue reagent. For the analysis of differential gene expression, SH-SY5Y cells were plated onto Petri dishes ( $\varnothing 100 \mathrm{~mm}$ ) and, the day after this plating, the culture medium was replaced with the same medium (10 ml) supplemented with $2 \%$ FBS. After $24 \mathrm{~h}, 1 \mathrm{ml}$ of Gelsemium s. or control dilution was added to the cell culture and maintained at $37^{\circ} \mathrm{C}$ with $5 \% \mathrm{CO}_{2}$ in a humidified atmosphere (90\% humidity) for a further $24 \mathrm{~h}$. Four replicate experiments were carried out under identical conditions. In three experiments, Gelsemium s. 2c and the respective control were tested on IMR-32 neuroblastoma cell line (CCL-127 purchased from ATCC, Manassas, VA, USA), grown and treated under the same conditions, except that EMEM medium (Lonza) was used instead of DMEM-F12.

\section{Cell viability assay}

The cytotoxic action of the Gelsemium s. or ethanol dilutions on SH-SY5Y cells was assessed by the WST-1 assay [38]. In this test, cell viability is reflected by mitochondrial dehydrogenase activity in cleaving tetrazolium salts (WST-1 reagent, Roche Molecular Biochemicals -Mannheim, Germany) to soluble formazan. A total of 20,000 cells per well were seeded in a 96-well microplate in the DMEM-F12 medium with 10\% FBS and left to adhere for $16 \mathrm{~h}$. Then the culture medium was replaced with $200 \mu$ l of the same medium supplemented with $2 \%$ FBS. Drug and control solutions $(22 \mu \mathrm{l})$ were then added (6 replicates of each condition for each plate) and the plate was incubated at $37^{\circ} \mathrm{C}$ in a $5 \% \mathrm{CO}_{2}$ atmosphere. After $24 \mathrm{~h}, 1: 10(\mathrm{v} / \mathrm{v})$ pre-warmed WST-1 solution was added to the cells and the plate incubated for $3 \mathrm{~h}$. The absorbance (OD) of the samples was measured using a Victor3 multilabel reader (PerkinElmer, Shelton, CT, USA ) at $450 \mathrm{~nm}$, and cell metabolic activity was evaluated as the difference between $\mathrm{OD}$ at $3 \mathrm{~h}$ and $\mathrm{OD}$ at T0.

\section{Measurement of intracellular $\mathrm{Ca}^{2+}$ concentration}

Increase in intracellular $\mathrm{Ca}^{2+}$ was monitored as described [39] with minor modifications. SH-SY5Y cells were inoculated in 96-well black microplates (flat transparent bottom) with a density of 80,000 cells/well and left to adhere for $16 \mathrm{~h}$. The culture medium was removed from the wells, and the cells were washed with warm Hank's basal saline solution (HBSS, Sigma-Aldrich) with 20 mM Hepes (Sigma-Aldrich) and incubated with loading medium $(100 \mu \mathrm{l} /$ well $)$ at $37^{\circ} \mathrm{C}$ for $40 \mathrm{~min}$ in the dark, with $5 \% \mathrm{CO}_{2}$ in a humidified atmosphere. The loading medium was made up of the $\mathrm{Ca}^{2+}$-sensitive dye Fluo-4 AM $(4.5 \mu \mathrm{M})$ (Invitrogen, Paisley, UK) and probenecid (2.5 $\mathrm{mM}$ )
(Invitrogen) in HBSS. After incubation, the cells were washed and incubated with warm HBSS containing $2.5 \mathrm{mM}$ probenecid at $37^{\circ} \mathrm{C}$ for $30 \mathrm{~min}$ in the dark. At the indicated time, carbachol (Sigma-Aldrich) was added at the final concentrations of 1, 5, 10, $20 \mu \mathrm{M}$ and the plate was transferred to a Victor3 multilabel reader (PerkinElmer) for the measurements. Each dose was measured in triplicate and compared with a blank for about 15 min using the kinetic mode.

\section{RNA isolation and quality controls}

Cells exposed to $24 \mathrm{~h}$ Gelsemium s. or control solutions were harvested with trypsin-EDTA-PBS treatment (5 $\mathrm{mg} \mathrm{L}^{-1}$, Lonza) and counted. Then, total RNA was promptly extracted (from $3.5 \times 10^{6}$ cells) using the Qiagen RNAeasy Mini Kit (Qiagen GmbH, Hilden, Germany) following the manufacturer's instructions (Animal cells Spin protocol), including genomic DNA elimination step in column. RNA extraction was performed within $20 \mathrm{~min}$ from cell detachment. The RNA samples were concentrated by precipitation with 2.5 volumes of ice-cold absolute ethanol in presence of $0.3 \mathrm{M} \mathrm{Na}$ acetate. RNA yield was determined by a NanoDrop 1000 spectrophotometer (Thermo Scientific, Wilmington, DE, USA) and RNA integrity was then evaluated using the 2100 Bioanalyzer (Agilent, Santa Clara, CA, USA).

\section{cDNA synthesis, labelling and microarray hybridisation}

Microarray analysis was performed on a $12 \times 135 \mathrm{~K}$ (i.e. made with 12 sub-arrays and 135,000 probes per sub-array) human NimbleGen microarray chip (Roche NimbleGen, Madison, WI, USA, catalogue no. 05543789 001, design 100718_HG18_opt_expr_HX12) containing 45033 genes with 3 probes per target gene. The microarray is based on HG18, Build 36; cDNA synthesis, labelling and hybridization were performed according to manufacturer's protocols (http://www.nimblegen.com/support/dna-microarray-support.html; see file 05434505001_NG_Expression_UGuide_v6p0.pdf). Briefly, $10 \mu \mathrm{g}$ total RNA for each sample was used to synthesize cDNA using a SuperScript doublestrandedcDNA synthesis kit (Invitrogen) with oligo(dT) primers for amplification. After further evaluation of integrity and yield with the Bioanalyzer, the cDNA samples were labelled with Cy3 using a NimbleGen One-Color DNA labelling kit (Roche). $4 \mu \mathrm{g}$ of Cy3-cDNA were hybridized on each subarray for $16 \mathrm{~h}$ at $42^{\circ} \mathrm{C}$. All 12 samples $(6$ Gelsemium $s$. and 6 controls) for each experiment were hybridized in the same chip and processed simultaneously. Sample tracking controls were used to ensure against cross contaminations or erroneous loading in the array. The procedure was repeated for four and three biological replicates with $\mathrm{SH}$ SY5Y and IMR-32 cells, respectively.

The arrays were scanned with a GenePix 4400A scanner (Molecular Devices Corp., Sunnyvale, CA, USA) and 
scanned images (TIFF format) were then imported into the NimbleScan software for grid alignment and expression data analysis. Quality control of the array images was performed on the basis of the parameters reported in the Experimental Metrics Report as indicated by the NimbleGen Software Guide v3.0. The parameters assessed the absence of spatial biases of the fluorescence within each subarray, the homogeneity of the mean signal among the subarrays and the acceptable level of background (empty and random spots) before background correction and intra-array normalization. Gene calls were generated using the Robust Multichip Average (RMA) algorithm as described by Irizarry et al. [39]. Normalization was performed using quantile normalization as described by Bolstad et al. [40]. The data have been deposited in NCBI's Gene Expression Omnibus [41] and are accessible through GEO Series accession number GSE42236.

\section{Real time quantitative RT-PCR}

A qRT-PCR analysis was performed on SH-SY5Y neuroblastoma treated with Gelsemium s. 2c or the control 2c, to verify the gene expression profile of AIPL1, ALPK3, BIRC8, C1ORF167, DDl1, EN2, GALR2, GPR25, LST1, OR4X1, OR5C1, KLKBL4 and TAC4 genes, that were identified by microarray analysis. UPL hydrolysis probes and primers (RealTime ready Assays, Roche) were specifically designed and experimentally validated to match the differentially expressed transcript Id identified by Nimblegen microarray. One $\mu \mathrm{g}$ of RNA previously extracted (Qiagen), quantified spectrophotometrically (Nanodrop) and further DNase treated (Turbo DNA-free kit, Ambion), was reverse transcribed using Transcriptor First Strand Synthesis kit with oligo dT (Roche) and subsequently $250 \mathrm{ng}$ of cDNA were pre-amplified with a pool of primers following the instruction of RealTime Ready cDNA Pre-Amp Master kit (Roche). The pool consisted of the RealTime Ready Assays primers specific for genes listed above diluted 1:10 each in water PCR-grade. One to 20 diluted pre-amplified cDNA was put in qPCR with the gene specific RealTime Ready Assays and with FastStart Universal Probe Master-Rox (Roche). Briefly, the reaction mixture consisted of $10 \mu \mathrm{l}$ of $2 \mathrm{X}$ FastStart Universal Probe Master-Rox, $1 \mu \mathrm{l}$ of 20X RealTime ready Assay, $1 \mu \mathrm{l}$ of template cDNA diluted 1:10 and nuclease free water up to $20 \mu \mathrm{l}$. Three different technical replicates were analyzed for each cDNA sample in the same assay and $\beta$-actin (ACTB gene ID: 60 ) and $\beta-2$ microglobulin (B2M gene ID: 567) were used as housekeeping genes for the normalization. The StepOne Plus Real-time PCR System (Applied Biosystem, USA) was used to monitor the hydrolysis probe signal generated with a standard thermal profile specific for this kind of probe, i.e. $10 \mathrm{~min}$ of $95^{\circ} \mathrm{C}$, followed by 40 cycles of $95^{\circ} \mathrm{C} 15 \mathrm{sec}, 1 \mathrm{~min}$ of $60^{\circ} \mathrm{C}$. The quantification cycle $(\mathrm{Cq})$ was determined by using the log view of the $\Delta \mathrm{Rn}$ amplification plots, normalized by the internal ROX reference dye, whereas the relative fold change (FC) in the expression levels was determined with the $\Delta \Delta C q$ method, taking the mean of the three PCR replicates. Data are presented as Log2 transformation of FC.

\section{Statistics}

The experimental model had dose-response setup, including 6 dilutions of Gelsemium s. and 6 corresponding controls. The main working variable was the $\log 2-$ transformed fluorescence value of microarray analysis of gene expression. Data from 4 independent experiments were considered. Expecting effects to diminish with increasing dilution, we focused to a pair-wise comparison between Gelsemium s. dilutions and the vehicle controls instead of an overall comparison analysis. Two consecutive statistical approaches were followed. The first approach analyzed the complete transcriptome dataset and was aimed to select the DEGs that were most significantly affected by treatment at the highest dose; linear model (Limma) was applied to compare the expression values from Gelsemium 2c treated and the mean of controls (see details below). The second approach analyzed only the expression values of the selected DEGs when treated with highly diluted drugs or the corresponding controls. The main focus was to verify the null hypothesis that the higher Gelsemium s. dilutions did not affect the expression of the genes compared to control. For this analysis we used Friedman test as nonparametric ANOVA and Fisher's exact test (see details below). The tests analyzed the distributions of the fold changes in the down- or up-regulated DEGs and determined whether the direction of effect for the DEGs detected in the 2c concentration was maintained across all other dilutions $(3 \mathrm{c}-30 \mathrm{c})$.

In the first part of analysis, a linear modelling approach and the empirical Bayes statistics as implemented in the Limma package [42] were employed for differential expression analysis. The Limma test was applied to compare Gelsemium s. dilutions with controls, or controls between each other. The p-values were adjusted for the False Discovery Rate (FDR) on the 45033 cases using the Benjamini and Hochberg method [43]. No pre-filtering to the dataset (variant-based or minimal expression-based) was applied to avoid a-priori loss of results when studying minimal doses of drug. Log2 fold change was calculated as Log2-transformed fluorescence value of Gelsemium s. dilutions minus Log2-transformed fluorescence value of mean of controls. DEGs were selected as significant and interesting for further analysis if their absolute value of $\log 2$ fold change (|log2 fold change|) was higher than 0.5 and the adjusted $p$-value was $<0.05$.

In the second part of the analysis, the significant DEGs in $2 c$ treatment were divided in two groups (considered 
as gene-sets) according to their direction of change, including down- and up-regulated genes; data referred to the same dilution (from $2 \mathrm{c}$ to $30 \mathrm{c}$ of both treatments and respective controls) were joined, treating the single gene as a statistical unit and the mean of four replications as the corresponding datum. Statistical significance of the overall differences between expression profiles of gene-sets (down- and up-regulated) in various treatment conditions was calculated by the Friedman multi-sample test using SPSS software, version 17 (SPSS Inc., Chicago, IL, USA). The Friedman test is a nonparametric test for multiple related samples (in our case, the expression level of multiple matched samples from cells treated with 6 Gelsemium s. dilutions or 6 control solutions) that checks the null hypothesis that multiple ordinal responses come from the same population. Following a significant result of Friedman test, frequency of downregulated vs upregulated genes were calculated; |log2 fold change| lower than or equal to 0.05 were considered to be null. The significance of distributions for each dilution was analyzed by the Fisher's exact test, which calculates the exact probability of getting, only by chance, the observed values or more extreme ones. A randomly selected set of 49 genes, for comparison of frequency of down-regulated vs up-regulated genes with the Gelsemium s.-specific gene-set, was generated from the whole microarray dataset, using the specific function of the SPSS 17 software.

Gene expression profiles were clustered by the k-means clustering method and Pearson correlation metrics using the MeV 4.8.1 software (http://www.tm4.org/mev.html). The application "Figure of merit" (FOM) was used to set the number of clusters that best fit the dataset variability [44]. The FOM measures the average intra-cluster variance of the observations, estimating the mean error using predictions based on the cluster averages [45]. Gene functional classification and enrichment analysis were performed by DAVID Bioinformatics Resources 6.7 (http:// david.abcc.ncifcrf.gov) [46]. Results of viability assay were analyzed by ANOVA and t-test comparing data from each Gelsemium s. dilution (G2c, G3c, G4c, G5c, G9c and G30c) with the corresponding controls ( $\mathrm{n}=$ 12 replicates for each group).

\section{Results}

\section{Cell morphology and function}

The SH-SY5Y neuroblastoma cells used in the assay exhibited a neuron-like shape with visible axons and junctions when grown in Petri dishes (Figure 1A). To assess the basal neuronal reactivity of these cells, the culture was stimulated with different doses of the acetylcholine-analogue carbachol and the change in concentration of intracellular calcium was measured with the $\mathrm{Ca}^{2+}$-sensitive probe Fluo4-AM. As shown in Figure 1B, the cells were sensitive to the varying amounts of the neurotransmitter, and intracellular calcium concentration increased in a dose-dependent way.

\section{UV-VIS Spectra of Gelsemium s.}

Figure 2 shows the absorption spectra of some of the preparations used in this study. The spectrum of the lowest dilution (1c) was considered as marker for the actual presence of plant extract. Spectra of the subsequent dilutions checked the effectiveness of the $100 \times$ dilution steps, i.e. verified that a) the lower dilutions (from pharmaceutical factory and prepared in the laboratory) were comparable and b) the provided higher potencies were effectively diluted. The original 1c dilution supplied by the factory (panel A) was characterized by high absorption in UV region near $210 \mathrm{~nm}$ and by two absorption shoulders at $280 \mathrm{~nm}$ and $330 \mathrm{~nm}$; no absorption in the visible spectrum region above $450 \mathrm{~nm}$ was detected. The original $2 \mathrm{c}$ dilution (panel B) showed a qualitatively similar spectrum, but with an absorption intensity about 100 times lower than that of 1c, indicating that the dilution was done correctly during the preparation process. The $3 \mathrm{c}$ dilution (panel $\mathrm{C}$ ) has no significant absorption over the background noise level, which is as expected since it was produced by a $100 \times$ dilution of 2c. The 2c solution prepared in the laboratory by a $100 \times$ dilution of the original $1 c$ in water (panel D) shows a spectrum with absorption features corresponding roughly to $1 / 100$ of the spectrum of (panel A), indicating that the final dilution of the samples for use in cell assays was done correctly. The spectra of higher dilutions were below the detection limit for this technique (data not shown).

\section{Effect of Gelsemium s. dilutions on SH-SY5Y viability}

To evaluate whether the Gelsemium s. dilutions had any toxic effects, the viability of SH-SY5Y cells after exposure to drug dilutions for $24 \mathrm{~h}$ was checked by WST-1 spectrophotometric assay. As can be seen in Figure 3, Gelsemium s. dilutions did not impair cell viability as compared to controls. No significant differences in cell viability were observed between cells treated with the ethanol control solution $0.03 \%(\mathrm{v} / \mathrm{v})$ and untreated cells (data not shown).

\section{Gene expression changes induced in SH-SY5Y cells}

Global changes in gene expression produced by exposure to low doses or high dilutions of Gelsemium s. extracts in human SH-SY5Y neuroblastoma cells were investigated by microarray analysis, and the results selectively compared with the gene expression of cultures exposed to the vehicle solutions. Cells were incubated for $24 \mathrm{~h}$ with the 6 dilutions of Gelsemium s. or the corresponding controls, after which the 12 samples were rapidly processed and 
A

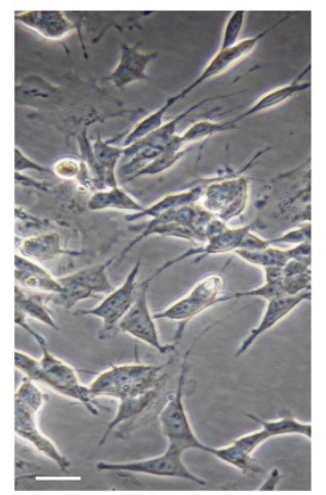

B

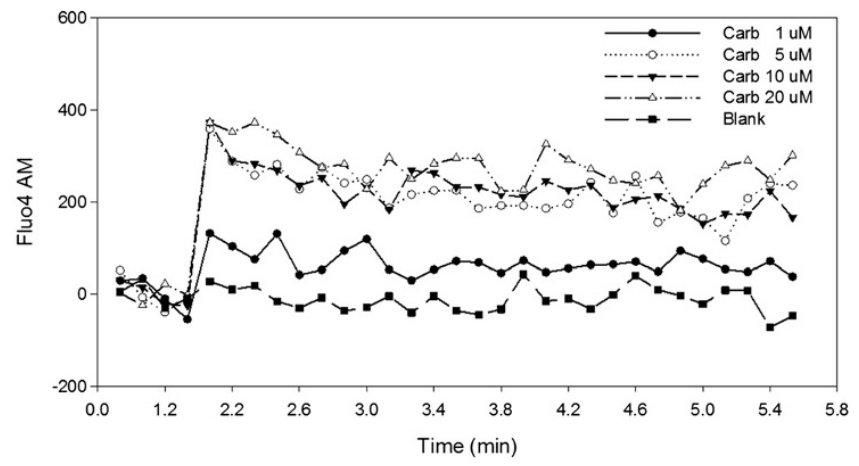

Figure 1 Morphological and functional properties of SH-SY5Y neuroblastoma cells used in the assay. A. Phase contrast micrograph of adherent cells cultured in Petri dishes. Bar, $10 \mu \mathrm{m}$. B. Spectrofluorometric measurement of intracellular calcium changes induced by carbachol at the specified doses.

tested simultaneously on a $12 \times 135 \mathrm{~K}$ NimbleGen chip. After running a total of 4 experiments, differential gene expression was analyzed. The general correlation values among the 48 normalized sub-arrays compared in the analysis (12 conditions and 4 replicates) was very high (Pearson correlation coefficient $>97 \%$, mean $=0.988$ ), demonstrating the reproducibility of the experiments.

Preliminary Limma analysis, performed only with the control samples, excluded the presence of significant differences among the different diluted/succussed vehicles (adjusted $p>0.05$ ), and authorized merging them in a unique control group. The difference in expression (Log2 fold change) between Gelsemium s. and the average of the controls was calculated for each dosage, and the results were compared to detect any trend in the response to increasing drug dilutions. In general, the range of changes in gene expression was quite narrow: out of a total of 45033 transcripts, in Gelsemium s. 2c and 3c,
A

Abs

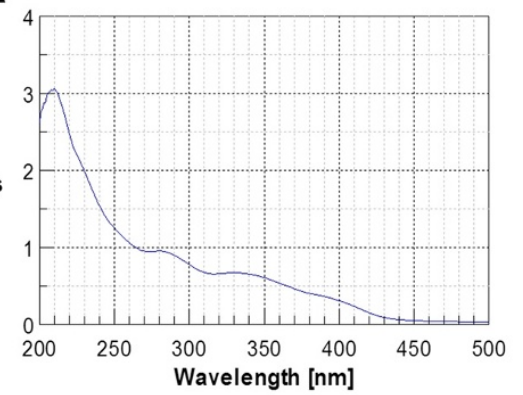

C

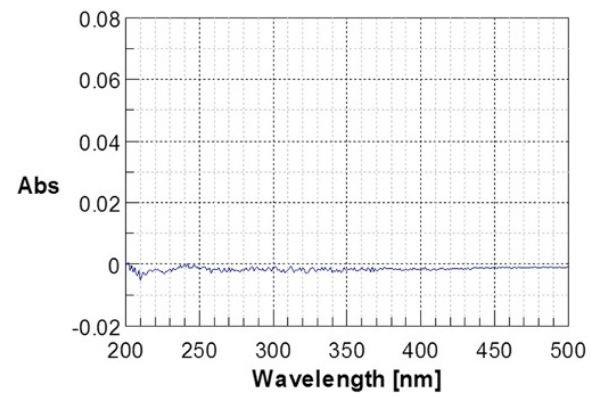

B

Abs

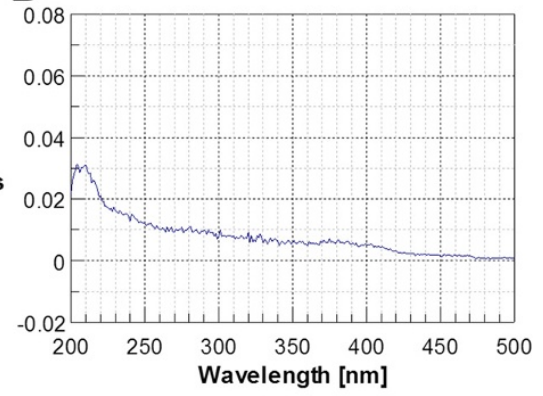

D

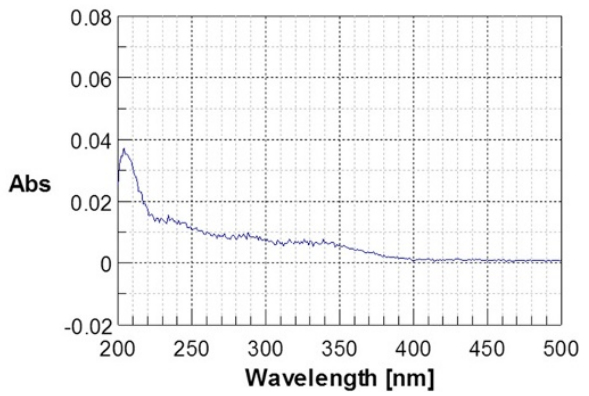

Figure 2 UV-vis spectra of representative Gelsemium s. solutions. A: Gelsemium s. 1c dilution supplied by the manufacturer, B: Gelsemium s. 2 c dilution supplied, C: Gelsemium s. 3 c dilution supplied, D: Gelsemium s. 2c dilution prepared by $100 \times$ dilution of solution A and used in the experiments. 


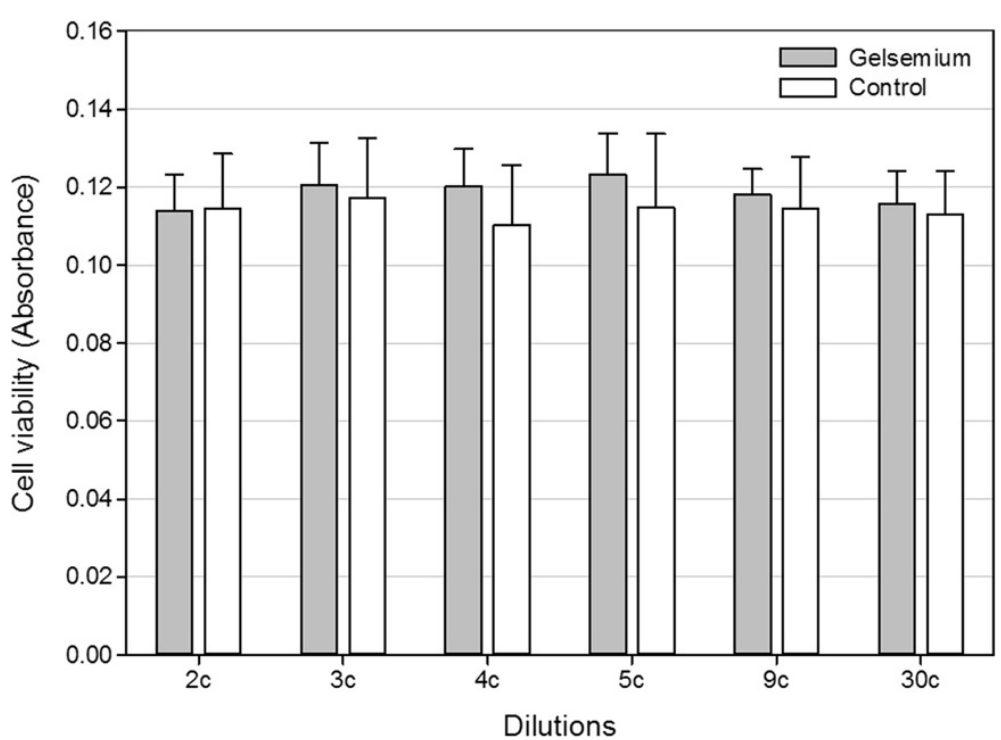

Figure 3 Effects of Gelsemium s. on SH-SY5Y cell viability. Cell viability was determined by WST assay after $24 \mathrm{~h}$ treatment with Gelsemium s. or Control dilutions. Values in abscissa are mean absorbance values \pm SD $(n=6)$.

the lowest dilutions, only a small subset of genes (577 and 165 , respectively) showed $\mid \log 2$ fold change $\mid>0.5$. Among these DEGs, exposure to Gelsemium s. 2c promoted a statistically significant down-expression of 49 genes, while 7 genes were overexpressed (Limma analysis with adjusted $p<0.05$ ) (Table 1 ). In general, mean fold changes in the mRNAs levels of cells treated with Gelsemium s. were small and only 4 genes showed |log2 fold change $\mid>0.8$. No significant changes of housekeeping genes were recorded, as expected.

\section{Gene expression changes induced in IMR-32 cells}

To verify whether the effect of Gelsemium s. could be reproducible in different types of neurocytes, the Gelsemium s. 2c treatment and the corresponding ethanol controls were applied to the IMR-32 human neuroblastoma cell line. After three replicate experiments, the analysis did not detect significant changes between Gelsemium s. and controls if the cut-off values of $\mid \log 2$ fold change $\mid>0.5$ and adjusted $p<0.05$ (Limma analysis with Benjamini and Hochberg correction) were applied. As observed in the SH-SY5Y cells, the global gene expression change in the IMR-32 cells was slight, since only 116 genes $(0.25 \%$ of the transcripts) registered | $\log 2$ fold change| $>0.5$ (compared to the 577 genes in SH-SY5Y cells, corresponding to $1.3 \%$ of total). In any case, as shown in Figure 4, the changes in the 56 selected genes of SH-SY5Y cells were in the same direction in the IMR32 cells. In fact, 44 of the 49 genes that were down-regulated in SH-SY5Y also had a negative fold change in IMR-32, and 6 of the 7 genes that were up-regulated in SH-SY5Y also had a positive fold change in IMR-32. These data show that the expression of the same gene-set was also modified in a second type of neurocyte, although the most sensitive model for detecting the effect of Gelsemium $s$. is the SH-SY5Y cell line.

\section{Real time quantitative PCR: Validation of the microarray data}

To validate the microarray results, RT-qPCR analysis was performed on SH-SY5Y cells exposed to the Gelsemium s. $2 \mathrm{c}$ and the corresponding control. RT-PCR was carried out on the cDNA obtained from the RNA samples of 3 replicate experiments tested by microarray assay. Among the list of DEGs (see Table 1) we selected 13 genes according to the extent of expression changes and their potential relevant functions (e.g. transcription factors, G-protein coupled receptors or neuropeptides) (Table 2). The genes investigated by quantitative PCR generally confirmed the changes obtained by microarray assay. DDI1, EN2, GALR2, GPR25, OR5C1, Klkbl4 and TAC4 genes were downregulated in Gelsemium s. 2c samples compared to Control $2 \mathrm{c}$ in the three replicated experiments. Negative fold changes were observed also with BIRC8 genes, although with variable values. The applied RT-qPCR assays could not detect AIPL1, C1orf167, LST1 and OR4X1, because their expression was under the sensitivity of the assay, and did not confirm the up-regulation of ALK3 gene.

\section{Statistical analysis of data from Gelsemium s. dilutions and controls}

SH-SY5Y cells treated with higher Gelsemium s. dilutions (3c, 4c, 5c, 9c, 30c) showed changes in gene expression due to treatment, which were rated by Limma 
Table 1 Differentially expressed genes after treatment with Gelsemium s. 2c in SH-SY5Y cells

\begin{tabular}{|c|c|c|c|c|c|}
\hline Gene ID & Transcript ID & Symbol & Log2 fold change & $p^{1}$ & Description \\
\hline 7940 & AF000424 & LST1 & $-0.84 \pm 0.14$ & 0.04 & Leukocyte specific transcript 1 \\
\hline 390113 & NM_001004726 & OR4X1 & $-0.83 \pm 0.06$ & 0.01 & Olfactory receptor, family 4 , subfamily $X$, member 1 \\
\hline 23746 & AJ830742 & AIPL1 & $-0.82 \pm 0.16$ & 0.04 & Aryl hydrocarbon receptor interacting protein-like 1 \\
\hline 284498 & AL833920 & C1orf167 & $-0.80 \pm 0.17$ & 0.05 & Chromosome 1 open reading frame 167 \\
\hline 221191 & AK058068 & $\mathrm{Klkb} / 4$ & $-0.79 \pm 0.12$ & 0.04 & Plasma kallikrein-like protein 4 \\
\hline 26658 & NM_012377 & OR7C2 & $-0.77 \pm 0.07$ & 0.01 & Olfactory receptor, family 7 , subfamily $C$, member 2 \\
\hline 112401 & BC039318 & $\mathrm{BIRC} 8$ & $-0.76 \pm 0.11$ & 0.00 & Baculoviral IAP repeat-containing 8 \\
\hline 2848 & NM_005298 & GPR25 & $-0.75 \pm 0.15$ & 0.02 & G protein-coupled receptor 25 \\
\hline 55803 & NM_018404 & ADAP2 & $-0.75 \pm 0.11$ & 0.02 & ArfGAP with dual PH domains 2 \\
\hline 386676 & NM_198690 & KRTAP10-9 & $-0.73 \pm 0.12$ & 0.04 & Keratin associated protein 10-9 \\
\hline 4353 & X04876 & MPO & $-0.72 \pm 0.15$ & 0.04 & Myeloperoxidase \\
\hline N/A & AY358413 & N/A & $-0.71 \pm 0.18$ & 0.02 & Homo sapiens clone DNA59853 trypsin inhibitor \\
\hline 392391 & NM_001001923 & $\mathrm{OR} 5 \mathrm{C} 1$ & $-0.71 \pm 0.05$ & 0.04 & Olfactory receptor, family 5 , subfamily $C$, member 1 \\
\hline N/A & AK094115 & N/A & $-0.70 \pm 0.11$ & 0.04 & Homo sapiens CDNA FLJ36796 fis, clone ADRGL2006817 \\
\hline 55287 & BC020658 & TMEM40 & $-0.70 \pm 0.15$ & 0.02 & Transmembrane protein 40 \\
\hline 54209 & NM_018965 & TREM2 & $-0.69 \pm 0.10$ & 0.02 & Triggering receptor expressed on myeloid cells 2 \\
\hline 150365 & AK097834 & RP5-821D11.2 & $-0.68 \pm 0.17$ & 0.02 & Similar to mouse meiosis defective 1 gene \\
\hline 400934 & NM_207478 & FLJ44385 & $-0.68 \pm 0.09$ & 0.04 & FL444385 protein \\
\hline 255061 & NM_170685 & TAC4 & $-0.67 \pm 0.14$ & 0.01 & Tachykinin 4 (hemokinin) \\
\hline 644065 & XM_931993 & LOC644065 & $-0.65 \pm 0.23$ & 0.04 & Hypothetical protein LOC644065 \\
\hline 1339 & NM_005205 & COX6A2 & $-0.64 \pm 0.17$ & 0.01 & Cytochrome c oxidase subunit Vla polypeptide 2 \\
\hline N/A & AK128093 & N/A & $-0.63 \pm 0.09$ & 0.04 & Homo sapiens cDNA FLJ46214 fis, clone TESTI4012623. \\
\hline 53841 & AY358368 & CDHR5 & $-0.63 \pm 0.11$ & 0.04 & Mucin-like protocadherin \\
\hline 9332 & NM_004244 & CD163 & $-0.63 \pm 0.18$ & 0.03 & CD163 molecule \\
\hline 441239 & XM_499305 & LOC441239 & $-0.63 \pm 0.22$ & 0.05 & Hypothetical gene supported by BC063653 \\
\hline 7164 & NM_001003397 & TPD52L1 & $-0.62 \pm 0.09$ & 0.02 & Tumor protein D52-like 1 \\
\hline 11136 & NM_014270 & SLC7A9 & $-0.62 \pm 0.09$ & 0.04 & Solute carrier family 7 member 9 \\
\hline 389084 & NM_206895 & UNQ830 & $-0.62 \pm 0.11$ & 0.04 & ASCL830 \\
\hline 400224 & XM_375090 & FLJ44817 & $-0.62 \pm 0.20$ & 0.04 & Similar to pleckstrin homology domain protein (5 V327) \\
\hline 647240 & XM_934559 & LOC647240 & $-0.60 \pm 0.06$ & 0.00 & Hypothetical protein LOC647240 \\
\hline 846 & BC104999 & CASR & $-0.59 \pm 0.06$ & 0.00 & Calcium-sensing receptor \\
\hline 116123 & NM_138784 & RP11-45 J16.2 & $-0.58 \pm 0.09$ & 0.04 & Flavin-containing monooxygenase pseudogene \\
\hline 644280 & XM_497769 & LOC644280 & $-0.58 \pm 0.06$ & 0.05 & Hypothetical protein LOC644280 \\
\hline 57452 & AB032956 & GALNTL1 & $-0.57 \pm 0.17$ & 0.05 & Alpha-D-galactosamine $\mathrm{N}$-acetylgalactosaminyltransferase \\
\hline 414301 & NM_001001711 & DDI1 & $-0.56 \pm 0.11$ & 0.04 & DDI1, DNA-damage inducible 1, homolog 1 (S. cerevisiae) \\
\hline 116535 & BC016964 & MRGPRF & $-0.55 \pm 0.17$ & 0.01 & MAS-related GPR, member F \\
\hline 8811 & NM_003857 & GALR2 & $-0.55 \pm 0.07$ & 0.04 & Galanin receptor 2 \\
\hline 10880 & NM_006686 & ACTL7B & $-0.55 \pm 0.12$ & 0.04 & Actin-like 7B \\
\hline 6368 & NM_145898 & CCL23 & $-0.55 \pm 0.11$ & 0.05 & Chemokine (C-C motif) ligand 23 \\
\hline 64581 & BC071746 & CLEC7A & $-0.54 \pm 0.08$ & 0.04 & C-type lectin domain family 7 , member A \\
\hline 644003 & XM_927256 & LOC644003 & $-0.54 \pm 0.11$ & 0.04 & Similar to Mucin-2 precursor (Intestinal mucin 2) \\
\hline 643514 & XM_931594 & LOC643514 & $-0.54 \pm 0.10$ & 0.03 & Hypothetical protein LOC643514 \\
\hline 374569 & XM_935431 & LOC374569 & $-0.54 \pm 0.07$ & 0.04 & Similar to Lysophospholipase \\
\hline 84504 & BC101635 & NKX6-2 & $-0.53 \pm 0.13$ & 0.03 & NK6 transcription factor related, locus 2 (Drosophila) \\
\hline
\end{tabular}


Table 1 Differentially expressed genes after treatment with Gelsemium s. 2c in SH-SY5Y cells (Continued)

\begin{tabular}{llllll}
\hline 732 & NM_000066 & C8B & $-0.53 \pm 0.06$ & 0.05 & Complement component 8, beta polypeptide \\
146336 & NM_182510 & FLJ32252 & $-0.52 \pm 0.03$ & 0.01 & Hypothetical protein FLJ32252 \\
150763 & BC042847 & LOC150763 & $-0.51 \pm 0.10$ & 0.04 & Hypothetical protein LOC150763 \\
2020 & NM_001427 & EN2 & $-0.51 \pm 0.08$ & 0.04 & Engrailed homolog 2 \\
646258 & XM_929203 & LOC646258 & $-0.51 \pm 0.11$ & 0.04 & Hypothetical protein LOC646258 \\
154872 & NM_001024603 & LOC154872 & $0.51 \pm 0.10$ & 0.03 & Hypothetical LOC154872 \\
400866 & NM_001001789 & C21orf24 & $0.52 \pm 0.12$ & 0.05 & Chromosome 21 open reading frame 24 \\
9457 & NM_020482 & FHL5 & $0.55 \pm 0.19$ & 0.04 & Four and a half LIM domains 5 \\
55816 & NM_018431 & DOK5 & $0.56 \pm 0.04$ & 0.03 & Docking protein 5 \\
1446 & NM_001890 & CSN1S1 & $0.57 \pm 0.09$ & 0.04 & Casein alpha S1 \\
285600 & AK130941 & KIAA0825 & $0.63 \pm 0.06$ & 0.01 & KIAA0825 protein \\
57538 & NM_020778 & ALPK3 & $0.76 \pm 0.10$ & 0.01 & Alpha-kinase 3 \\
\hline
\end{tabular}

The table includes the genes with absolute Log2 fold change higher than 0.5. Each gene is described via GeneBank accession number (Gene ID), Gene symbol (Symbol), NimbleGen array transcript designation (Transcript ID). The log2 fold change of expression compared to mean control vehicle-treated cells is displayed as mean \pm SEM ( $n=4$ replicate experiments). ${ }^{1}$ adjusted $p$ value with Benjamini-Hochberg correction, obtained by Limma statistical test.

statistics above the $5 \%$ of FDR. Inspection of data reported in Table 3, concerning the expression profiles of the 56 DEGs (49 down-regulated and 7 up-regulated by Gelsemium s. 2c), highlights small expression changes (i.e. $\mid \log 2$ fold change| from 0.05 to 0.6 ) in $52,48,39,36$ and 48 genes of cells treated with Gelsemium s. 3c, 4c, $5 \mathrm{c}, 9 \mathrm{c}$ and $30 \mathrm{c}$ respectively. In order to analyze the statistical significance of these effects, a further approach was applied to these 56 DEGs. The hypothesis tested was to determine whether treated samples were different from controls or not and, in particular, if the direction of DEGs' changes detected in the 2c was maintained across all other dilutions rather than randomly distributed.

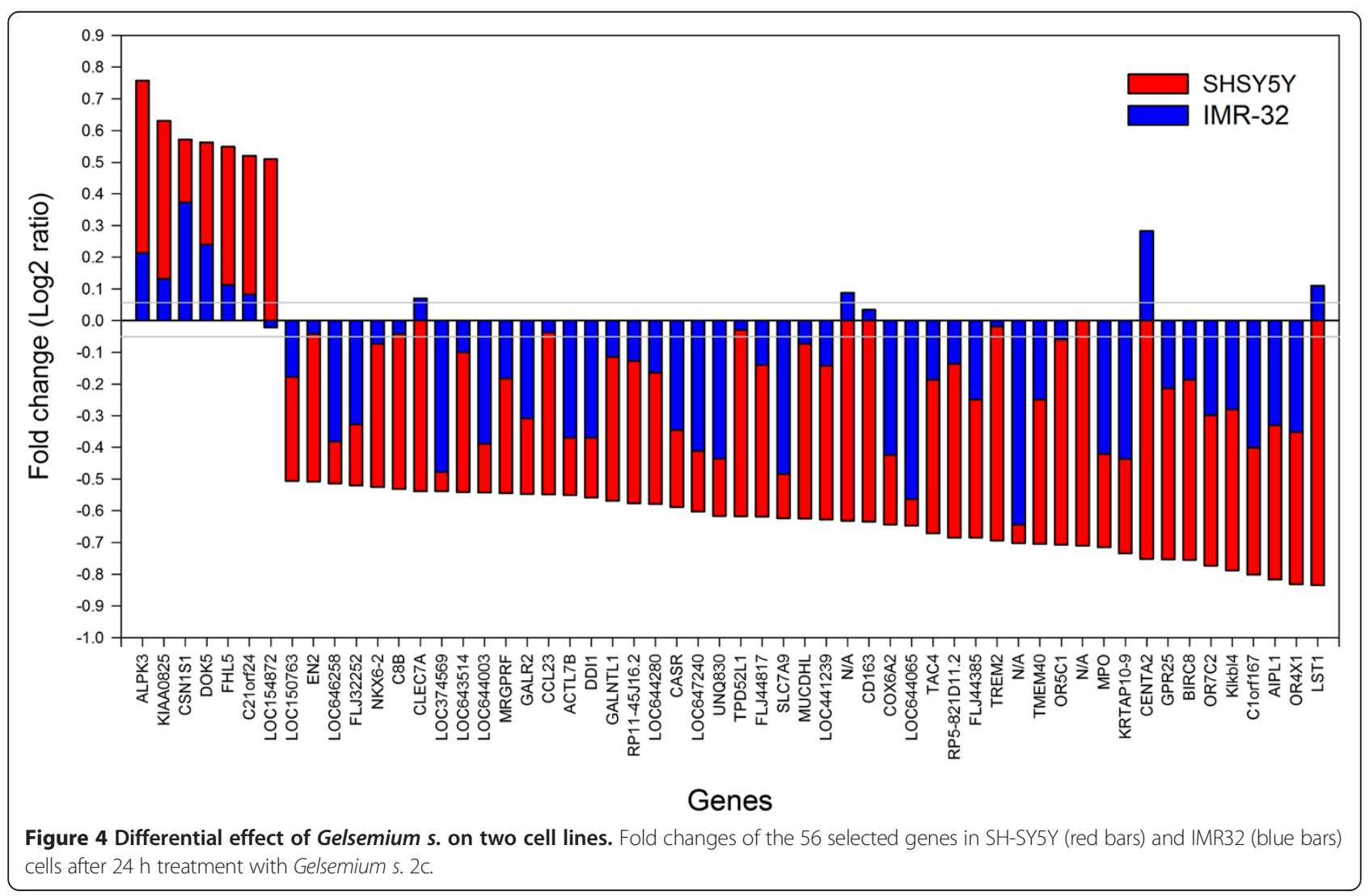


Table 2 Validation of microarray data of selected genes by RT-qPCR in Gelsemium s. 2 c versus Control $2 \mathrm{c}$ treated samples

\begin{tabular}{|c|c|c|c|c|c|c|c|c|c|c|c|}
\hline \multirow[b]{2}{*}{ Symbol } & \multirow[b]{2}{*}{ Gene ID } & \multicolumn{5}{|c|}{ Fold change microarray ${ }^{1}$} & \multicolumn{5}{|c|}{ Fold change RT-PCR ${ }^{2}$} \\
\hline & & R1 & R2 & R3 & Mean & SEM & R1 & $\mathrm{R} 2$ & R3 & Mean & SEM \\
\hline AIPL1 & 23746 & -0.60 & -0.59 & -1.06 & -0.75 & 0.13 & n.d. & n.d. & n.d. & & \\
\hline ALPK3 & 57538 & 1.16 & 0.04 & 0.96 & 0.72 & 0.28 & -0.87 & 0.24 & -0.25 & -0.29 & 0.26 \\
\hline $\mathrm{BIRC} 8$ & 112401 & -0.79 & -0.77 & -0.91 & -0.82 & 0.04 & 1.64 & -1.12 & -1.43 & -0.30 & 0.80 \\
\hline C1ORF167 & 284498 & -0.69 & -0.51 & -1.00 & -0.73 & 0.12 & n.d. & n.d. & n.d. & & \\
\hline DDI1 & 414301 & -0.93 & 0.02 & -1.30 & -0.74 & 0.32 & -0.62 & 0.16 & -1.23 & -0.56 & 0.33 \\
\hline EN2 & 2020 & -0.62 & -0.13 & -0.77 & -0.51 & 0.16 & -1.53 & -0.12 & -0.41 & -0.69 & 0.35 \\
\hline GALR2 & 8811 & -0.57 & -0.36 & -0.72 & -0.55 & 0.08 & -0.94 & -0.19 & -0.61 & -0.58 & 0.18 \\
\hline GPR25 & 2848 & -1.15 & 0.20 & -1.08 & -0.68 & 0.36 & -0.74 & 0.60 & -0.11 & -0.08 & 0.32 \\
\hline LST1 & 221191 & -0.71 & -0.76 & -1.18 & -0.88 & 0.12 & n.d. & n.d. & n.d. & & \\
\hline OR4X1 & 7940 & -0.96 & -0.55 & -0.74 & -0.75 & 0.10 & n.d. & n.d. & n.d. & & \\
\hline OR5C1 & 390113 & -0.84 & -0.33 & -0.79 & -0.66 & 0.13 & -0.95 & -0.51 & -1.00 & -0.82 & 0.13 \\
\hline Klkbl4 & 392391 & -0.05 & -0.70 & -1.04 & -0.60 & 0.24 & -1.10 & -0.17 & -0.41 & -0.56 & 0.23 \\
\hline TAC4 & 255061 & -0.23 & -0.28 & -1.34 & -0.62 & 0.30 & -1.14 & -0.10 & -0.46 & -0.57 & 0.25 \\
\hline
\end{tabular}

${ }^{1}$ Fold change was calculated as Log2 ratio between $\mathrm{G} 2 \mathrm{c}$ and $\mathrm{Ct} 2 \mathrm{c}$ expression values within the three replicated experiments (R1-R3); ${ }^{2}$ fold change was calculated as Log2 transformation of $2-\Delta \Delta C$ q between $\mathrm{G} 2 \mathrm{c}$ and $\mathrm{Ct} 2 \mathrm{c}$. N.d., not detectable.

\section{Statistical inference}

Expression values (mean of 4 experiments) of the 49 down- and 7up-regulated genes referred to the same dilution $(2 \mathrm{c} \div 30 \mathrm{c})$ of treatments and respective controls were compared. Additional file 1 reports Log2 data of all samples tested in this analysis. Friedman test estimated the overall variance among the samples and showed that the value distributions of the 12 different treatment groups (6 Gelsemium s. and 6 controls, $\mathrm{n}=49$ or $\mathrm{n}=7$ data for down-regulated and up-regulated genes, respectively) are significantly different $(p<0.0001)$. For a direct evaluation of the differences between Gelsemium $s$. treatments and the corresponding controls, Figure 5 shows the distribution of the fold changes in the 49 down-regulated genes for all the dilutions tested. Even though the size of the differences was distributed in a small range, the number of genes with negative fold change (Log2 Gelsemium s. $<$ Log2 control, blue in Figure 5) was systematically higher than the number of genes with positive fold change (Log2 Gelsemium s. > Log2 control, pink bars in Figure 5). In particular, the frequency of down-regulated vs up-regulated genes was 49 vs. 0 (100\% vs. $0 \%$ ) in 2c, as expected, 47 vs. 2 (96\% vs. $4 \%$ ) in 3c, 42 vs. 3 ( $86 \%$ vs. $6 \%)$ in 4 c, 38 vs. 3 (78\% vs. $6 \%)$ in 5c, 30 vs. 9 (61\% vs. 18\%) in 9c, 27 vs 7 (55\% vs. 14\%) in 30c. By applying Fisher exact test, the exact probability of the distributions, under the null hypothesis of indifference, was calculated and significant $p$ values resulted for all dilutions $(p<0.001$ for $3 c, 4 c$ and $5 c$ treatments, $p=0.0035$ for $9 \mathrm{c}$ and $p=0.004$ for $30 \mathrm{c}$ ). The absence of an equal scattering between the two signs (positive and negative fold changes) suggests that Gelsemium $s$. at high dilutions affects the expression of a significant portion of these genes. This conclusion is reinforced by a separate Fisher exact test carried out on a list of 49 genes randomly selected by the SPSS software from the 45033 transcripts (excluding the 56 DEGs); as reported in Additional file 2, no significantly different distribution of down-regulated or up-regulated genes in this random gene-set was observed with any Gelsemium s. dilution. Figure 6 reports the results for the panel of 7 up-regulated genes. Due to the small number of these genes, a distribution of fold changes could not be drawn and the statistical power of analysis was low. By Fisher exact test, a statistically significant prevalence of positive fold changes was observed only in $2 \mathrm{c}$, as expected, while the prevalence of positive fold changes in the other dilutions was not significant.

\section{Cluster analysis}

With the aim to describe the trends of gene expression when exposed to higher Gelsemium s. dilutions, k-means cluster analysis was applied on the Log2-fold change profiles of the 56 selected genes. The effect of all the tested Gelsemium s. dilutions was visualized as a heat map (Figure 7A) and as mean fold changes in each cluster of genes (Figure 7B). This allowed to identify gene subsets with similar expression profiles, and to detect some trends in the changes induced by increasing Gelsemium s. dilutions. Most of the genes down-regulated in the 2c-treated samples were also under-expressed in $3 \mathrm{c}$ and, to a varying extent, even in higher dilutions. The frequency of genes with negative fold changes was above $65 \%$ in all conditions, and in the sample treated with Gelsemium s. 30c the number of common genes that were down-regulated in all dilutions was 20 out of 49 (41\%). Cluster 1 contains 20 genes whose expression was down-regulated by the $2 \mathrm{c}$ 
Table 3 Fold changes of the 56 differentially expressed genes and the $\mathbf{4}$ housekeeping transcripts in cells treated with the 6 Gelsemium s. dilutions compared to means of controls

\begin{tabular}{|c|c|c|c|c|c|c|c|}
\hline Transcript ID & Symbol & G 2c & G 3c & G 4c & G 5c & G 9c & G 30c \\
\hline AB032956 & GALNTL1 & -0.57 & -0.20 & 0.16 & -0.13 & 0.02 & 0.09 \\
\hline AF000424 & LST1 & -0.84 & -0.18 & -0.20 & -0.05 & -0.14 & -0.23 \\
\hline AJ830742 & AIPL1 & -0.82 & -0.43 & -0.25 & -0.24 & -0.07 & -0.08 \\
\hline AK058068 & Klkbl4 & -0.79 & -0.41 & -0.17 & 0.11 & -0.15 & -0.07 \\
\hline AK094115 & N/A & -0.70 & -0.35 & -0.04 & -0.01 & 0.01 & -0.41 \\
\hline AK097834 & RP5-821D11.2 & -0.68 & -0.31 & -0.03 & -0.21 & -0.01 & 0.01 \\
\hline AK128093 & $\mathrm{N} / \mathrm{A}$ & -0.63 & -0.28 & -0.15 & 0.05 & -0.19 & -0.30 \\
\hline AL833920 & C1orf167 & -0.80 & -0.60 & 0.17 & -0.04 & 0.18 & -0.22 \\
\hline AY358368 & CDHR5 & -0.63 & -0.23 & -0.09 & -0.10 & -0.19 & -0.25 \\
\hline AY358413 & $\mathrm{N} / \mathrm{A}$ & -0.71 & -0.15 & 0.10 & 0.04 & 0.10 & -0.28 \\
\hline BC016964 & MRGPRF & -0.55 & -0.08 & -0.12 & -0.02 & 0.06 & 0.07 \\
\hline BC020658 & TMEM40 & -0.70 & -0.56 & -0.15 & -0.15 & 0.04 & -0.12 \\
\hline BC039318 & $\mathrm{BIRC} 8$ & -0.76 & -0.42 & -0.10 & -0.09 & 0.09 & -0.02 \\
\hline BC042847 & LOC150763 & -0.51 & -0.29 & -0.12 & 0.01 & -0.03 & -0.03 \\
\hline BC071746 & CLEC7A & -0.54 & -0.32 & -0.12 & -0.17 & 0.14 & 0.17 \\
\hline BC101635 & NKX6-2 & -0.53 & -0.56 & -0.12 & -0.12 & -0.14 & -0.12 \\
\hline BC104999 & CASR & -0.59 & -0.17 & -0.25 & 0.08 & 0.06 & -0.30 \\
\hline NM_000066 & $\mathrm{C} 8 \mathrm{~B}$ & -0.53 & -0.07 & 0.00 & -0.07 & -0.03 & -0.23 \\
\hline NM_001001711 & DDI1 & -0.56 & -0.21 & -0.27 & -0.31 & -0.17 & -0.26 \\
\hline NM_001001923 & OR5C1 & -0.71 & -0.28 & -0.22 & 0.08 & -0.13 & -0.24 \\
\hline NM_001003397 & TPD52L1 & -0.62 & -0.31 & -0.33 & -0.18 & 0.04 & -0.31 \\
\hline NM_001004726 & OR4X1 & -0.83 & -0.34 & 0.07 & 0.03 & -0.11 & -0.18 \\
\hline NM_001427 & EN2 & -0.51 & -0.33 & -0.22 & -0.06 & 0.02 & -0.13 \\
\hline NM_003857 & GALR2 & -0.55 & -0.31 & -0.13 & 0.02 & -0.01 & -0.13 \\
\hline NM_004244 & CD163 & -0.63 & -0.30 & -0.20 & -0.13 & 0.04 & -0.25 \\
\hline NM_005205 & COX6A2 & -0.64 & -0.39 & -0.38 & -0.07 & -0.30 & -0.17 \\
\hline NM_005298 & GPR25 & -0.75 & -0.41 & 0.02 & -0.05 & -0.02 & 0.02 \\
\hline NM_006686 & $A C T L 7 B$ & -0.55 & -0.44 & -0.13 & -0.02 & -0.01 & -0.15 \\
\hline NM_012377 & OR7C2 & -0.77 & -0.22 & -0.03 & -0.14 & -0.14 & -0.03 \\
\hline NM_014270 & SLC7A9 & -0.62 & -0.16 & -0.20 & 0.01 & -0.27 & -0.19 \\
\hline NM_018404 & ADAP2 & -0.75 & -0.40 & -0.30 & -0.19 & 0.04 & 0.03 \\
\hline NM_018965 & TREM2 & -0.69 & -0.34 & -0.08 & -0.14 & 0.09 & -0.20 \\
\hline NM_138784 & RP11-45 J16.2 & -0.58 & -0.29 & 0.06 & -0.05 & 0.20 & -0.17 \\
\hline NM_145898 & CCL23 & -0.55 & 0.03 & -0.09 & -0.20 & 0.02 & -0.20 \\
\hline NM_170685 & TAC4 & -0.67 & -0.30 & -0.19 & -0.06 & -0.13 & -0.24 \\
\hline NM_182510 & FLJ32252 & -0.52 & -0.33 & -0.26 & -0.10 & -0.10 & 0.02 \\
\hline NM_198690 & KRTAP10-9 & -0.73 & -0.29 & -0.10 & -0.03 & -0.28 & -0.13 \\
\hline NM_206895 & UNQ830 & -0.62 & -0.45 & -0.22 & -0.25 & -0.10 & -0.18 \\
\hline NM_207478 & FLJ44385 & -0.68 & -0.12 & -0.10 & -0.08 & -0.01 & -0.26 \\
\hline X04876 & MPO & -0.72 & -0.36 & -0.20 & 0.19 & -0.01 & -0.16 \\
\hline XM_375090 & FLJ44817 & -0.62 & -0.58 & -0.16 & 0.00 & -0.27 & -0.11 \\
\hline XM_497769 & LOC644280 & -0.58 & -0.19 & -0.20 & -0.02 & -0.07 & -0.05 \\
\hline XM_499305 & LOC441239 & -0.63 & -0.31 & -0.21 & -0.08 & -0.15 & -0.24 \\
\hline
\end{tabular}


Table 3 Fold changes of the 56 differentially expressed genes and the 4 housekeeping transcripts in cells treated with the 6 Gelsemium s. dilutions compared to means of controls (Continued)

\begin{tabular}{|c|c|c|c|c|c|c|c|}
\hline XM_927256 & LOC644003 & -0.54 & -0.57 & -0.31 & -0.19 & -0.27 & -0.10 \\
\hline XM_929203 & LOC646258 & -0.51 & -0.20 & -0.38 & -0.13 & -0.11 & -0.08 \\
\hline XM_931594 & LOC643514 & -0.54 & -0.23 & -0.11 & -0.01 & -0.21 & -0.16 \\
\hline XM_931993 & LOC644065 & -0.65 & -0.29 & -0.15 & 0.05 & -0.06 & -0.21 \\
\hline XM_934559 & LOC647240 & -0.60 & -0.40 & -0.23 & -0.16 & -0.08 & -0.08 \\
\hline XM_935431 & LOC374569 & -0.54 & -0.31 & -0.14 & -0.12 & -0.13 & -0.10 \\
\hline AK130941 & KIAA0825 & 0.63 & 0.30 & -0.07 & -0.07 & -0.06 & 0.15 \\
\hline NM_001001789 & C21orf24 & 0.52 & 0.19 & 0.08 & -0.01 & 0.00 & 0.21 \\
\hline NM_001024603 & LOC154872 & 0.51 & 0.13 & 0.15 & 0.05 & 0.06 & 0.21 \\
\hline NM_001890 & CSN1S1 & 0.57 & -0.04 & 0.03 & 0.30 & -0.07 & 0.11 \\
\hline NM_018431 & DOK5 & 0.56 & 0.04 & 0.03 & 0.01 & -0.02 & 0.31 \\
\hline NM_020482 & FHL5 & 0.55 & 0.38 & 0.01 & 0.10 & -0.02 & -0.08 \\
\hline NM_020778 & ALPK3 & 0.76 & 0.45 & 0.23 & 0.16 & 0.03 & 0.19 \\
\hline BC001601 & $\mathrm{GAPDH}^{1}$ & 0.01 & 0.09 & 0.02 & 0.10 & 0.03 & 0.04 \\
\hline NM_002046 & $\mathrm{GAPDH}^{1}$ & 0.09 & -0.14 & -0.02 & -0.10 & -0.01 & 0.00 \\
\hline BC009081 & $\mathrm{GAPDH}^{1}$ & 0.01 & -0.05 & 0.01 & -0.04 & -0.04 & -0.03 \\
\hline NM_001101 & $\mathrm{ACTB}^{1}$ & -0.04 & -0.05 & -0.05 & 0.05 & 0.02 & 0.00 \\
\hline
\end{tabular}

$\mathrm{N}=4$ experiments. ${ }^{1}$ Housekeeping transcripts.

dilution but which were less sensitive to higher dilutions, thus drawing a curve with asymptotic direction. Clusters 2 and 3 group together the genes also down-regulated by the Gelsemium s. high dilutions (but on which $5 \mathrm{c}$ or $9 \mathrm{c}$, respectively, had no effect), while cluster 4 includes the genes that were clearly responsive to Gelsemium s. 2c and $3 \mathrm{c}$ only. Cluster 5 contains the 7 up-regulated genes. Though significant up-regulation occurred only with 2c, most of those genes showed a similar effect trend in all dilutions.

\section{Functions of the modulated genes}

To obtain a functional classification, the 56 genes whose expression changed following exposure to Gelsemium in SH-SY5Y cells were subjected to analysis of the enriched annotation terms associated with the list. Table 4 reports the top enriched biological themes, particularly the GO terms discovered in the gene list by the DAVID software. A total of 28 genes (all down-regulated) from the list were classified into functional-related gene groups, while 17 IDs were unmapped in the DAVID database (see Table 1) because they have unknown functions. The remaining genes ( 3 up-regulated and 8 down-regulated) have known functions but were not rated as enriched in the list compared to the whole human transcriptome. The main group of functional features includes genes coding for membrane receptors, and in particular involved in G-protein coupled receptor (GPCR) transduction systems (OR4X1, CASR, OR5C1, CCL23, GPR25, GALR2, OR7C2, MRGPRF). Among these receptors, three have specific functions in olfactory transduction, attuned to detecting different types of stimuli including molecular vibrations [47]. The other clusters of genes may have a role in calcium signaling, inflammatory pathways, neuropeptide/receptor systems or as transcription factors. Of particular relevance for neuronal functions is the small but significant down-regulation of the gene TAC4 and GALR2. The first gene codes for the neuropeptide hemokinin-1 an analogous of substance-P [48], and the second for the receptor 2 of the neuropeptide galanin. Both are involved in the complex system of psyco-neuro-immune-endocrine axis which correlates the emotional responses with the hormone release and the immune functions $[49,50]$.

\section{Discussion}

Natural remedies are increasingly viewed as potentially valuable complements to conventional drugs in integrated treatment strategies for a number of disorders, and many consumers use natural health products alongside prescription medications [51]. Anxiety and depression are among the ailments most frequently reported by patients seeking complementary and alternative medical remedies and/or naturopathic care $[9,52,53]$. Gelsemium s. is a traditional remedy used in complementary and alternative therapies for treating patients who exhibit neurological complaints such as headache and anxiety-like symptoms $[9,52,53]$, but evidence-based clinical studies are few and with contrasting results $[53,54]$. 

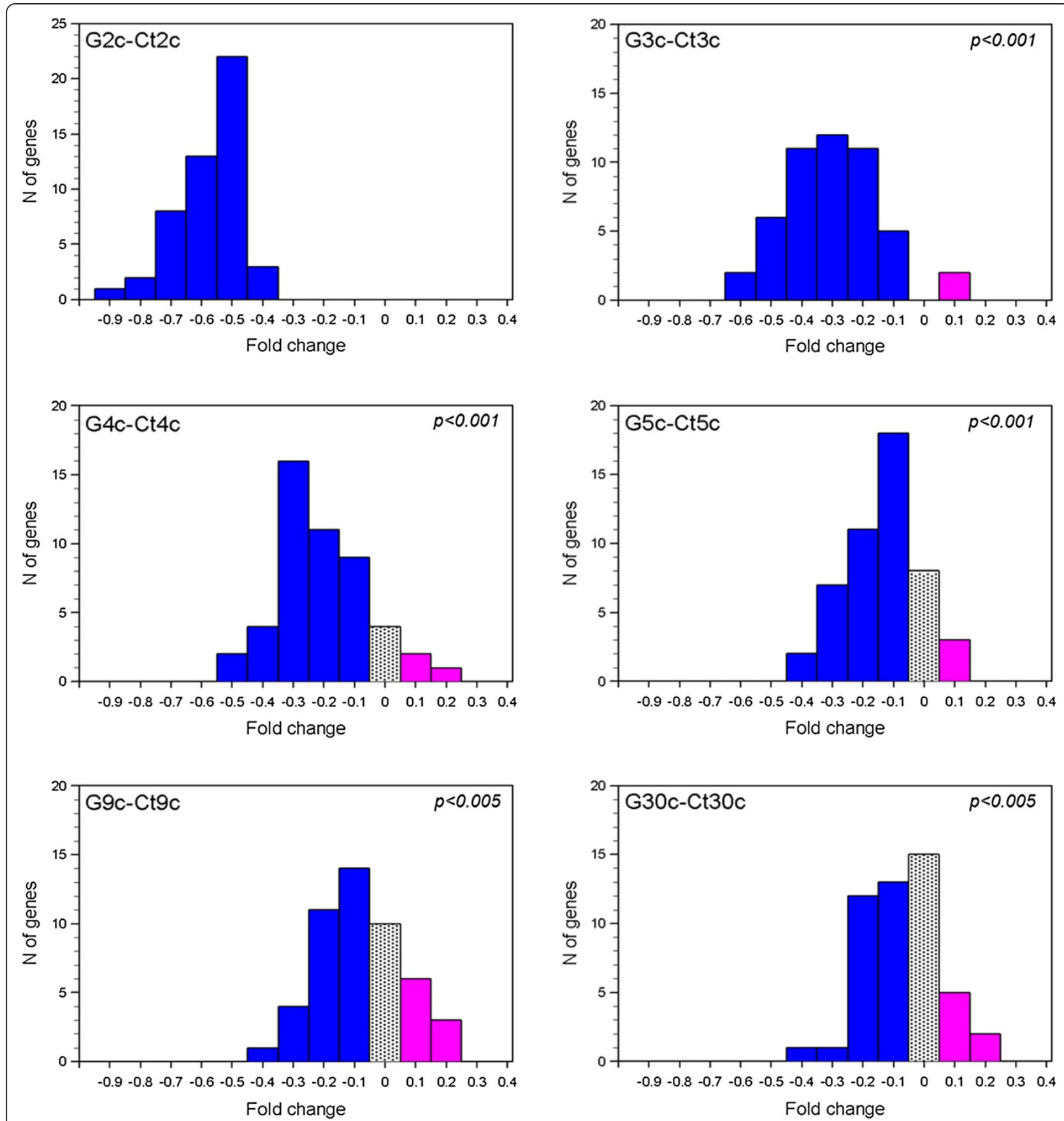

Figure 5 Frequency of fold change values in the down-regulated gene-set after Gelsemium s. treatments. In this analysis the 49 genes whose expression was down-regulated by Gelsemium s. 2c were considered. Mean Log2 fluorescence values from Gelsemium s.-treated samples (Gnc) and those from controls (Ctnc) were obtained from 4 microarray experiments and their difference was considered as fold change attributable to Gelsemium s. effect (see Methods). Absolute fold changes less than or equal to 0.05 were considered null. Blue bars: frequencies of genes with negative fold change ( $<-0.05$ ); grey bars: frequency of unaffected genes (from -0.05 to 0.05 ); pink bars: frequencies of genes with positive fold change (>0.05). Fisher exact $p$ values are reported in each panel except the G2c-Ct2c that are significant by definition.

Homeopathy is a 200-year-old therapeutic system that uses extremely small doses of various substances to stimulate auto-regulation and self-healing processes [55]. Although some conventional physicians find such notions implausible [56], use of highly diluted drugs from homeopathic pharmacopoeia has recently seen a worldwide revival $[57,58]$ and laboratory investigations are increasing in this field $[26,27]$, but scientific evidence of underlying molecular mechanisms is still lacking. Moreover, the experimental approaches adopted to study 


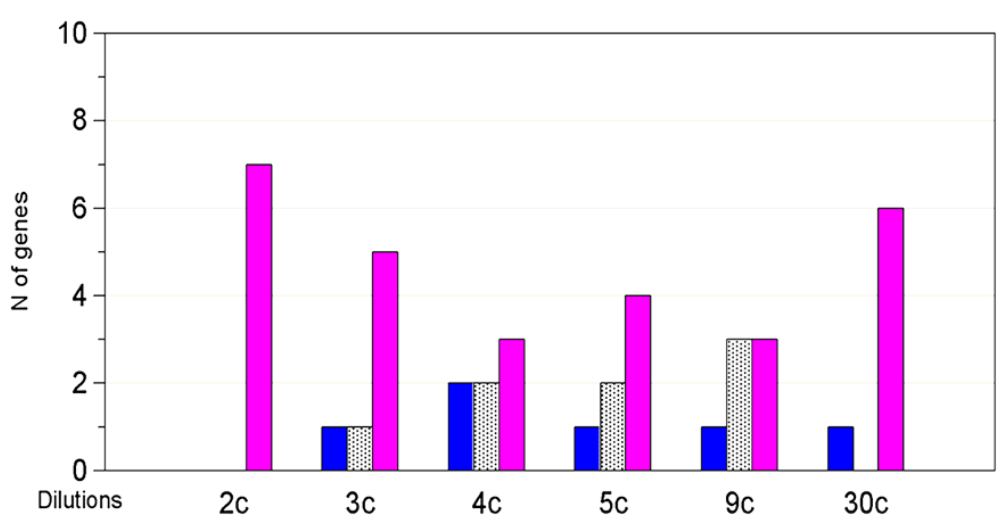

Figure 6 Number of genes modulated by Gelsemium s. dilutions in the panel of up-regulated genes. In this analysis the 7 genes whose expression was up-regulated by Gelsemium s. 2c were considered. Differences less than or equal to 0.05 were considered null. Blue bars: number of genes with negative fold change ( $<-0.05)$; grey bars: number of unaffected genes (from -0.05 to 0.05$)$; pink bars: number of genes with positive fold change ( $>0.05)$. Fisher exact test is not significant in any dilution except in the $2 c$ dilution that is significant by definition.

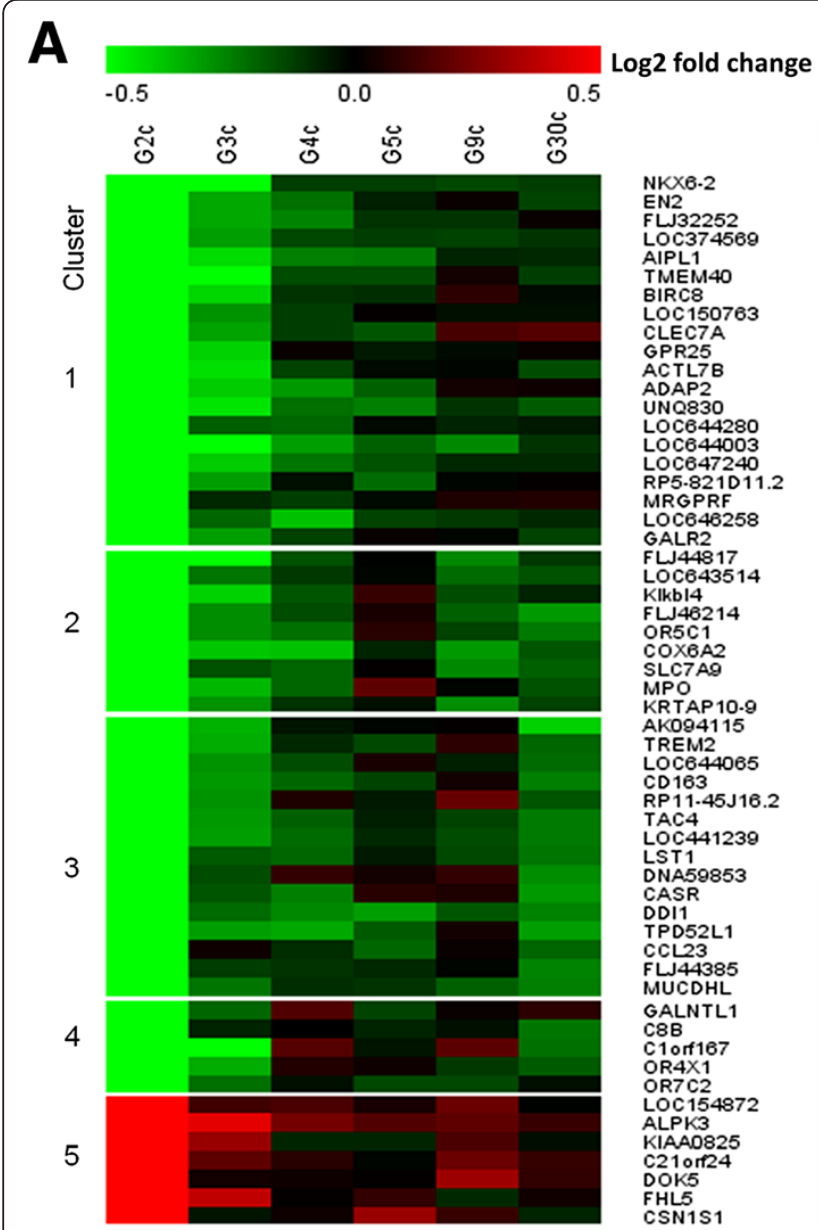

B
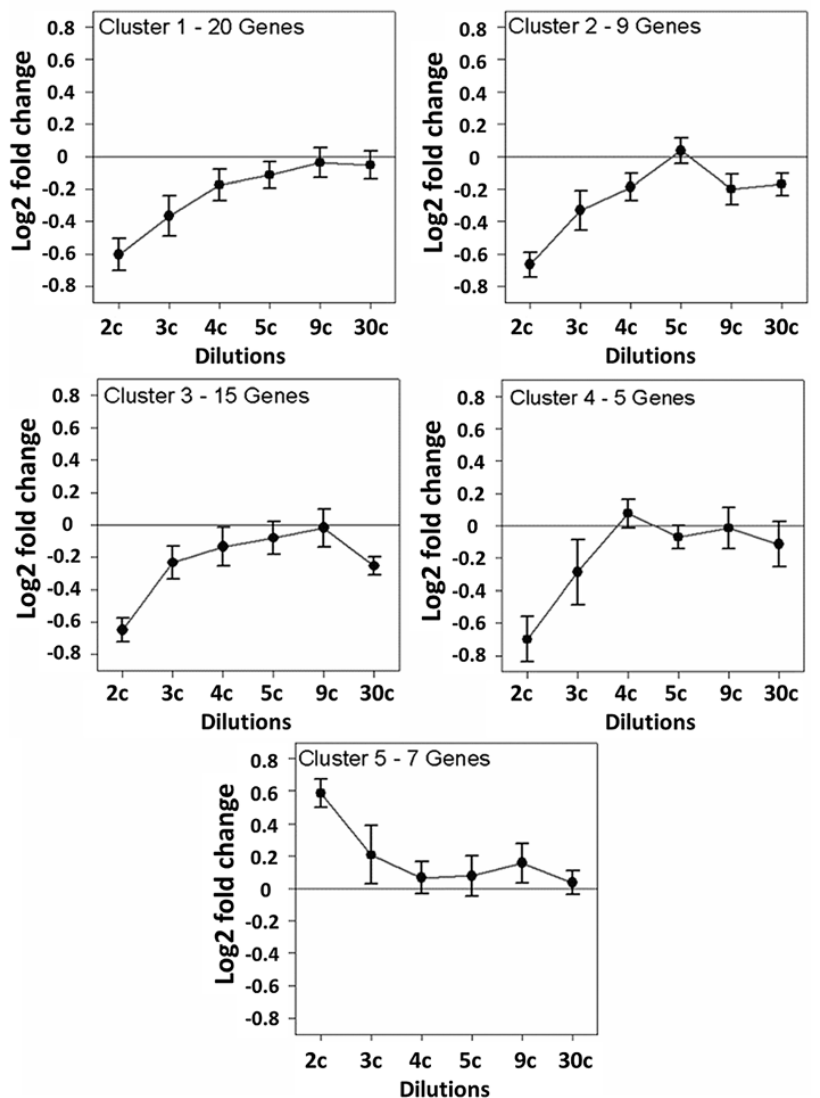

Figure $7 \mathrm{~K}$-mean clustering of the genes modulated upon exposure to Gelsemium s. dilutions. The expression profile of 56 genes significantly modulated by Gelsemium s. 2c was evaluated also upon exposure to increasing Gelsemium s. (G) dilutions. Fold change was calculated as the difference between Log2 fluorescence values of each Gelsemium s. dilution and the mean Log2 fluorescence of the controls. Data are means of 4 replicate experiments. A. K-mean clusters (KMC) visualized as a colour-coded heat map. The down-regulated genes (green) with similar expression profiles were grouped in 4 clusters and the up-regulated genes (red) in one cluster. B. Centroid graphs of the mean fold change of genes in the 5 clusters obtained in KMC analysis. 
Table 4 Top enriched annotation terms associated with the $\mathbf{5 6}$ genes differentially expressed upon exposure to Gelsemium s. 2c in SH-SY5Y cells

\begin{tabular}{|c|c|c|c|c|}
\hline Category & Annotation term & $P$ value & Genes & $\begin{array}{l}\text { Fold } \\
\text { enrichment }\end{array}$ \\
\hline SP_PIR_KEYW & receptor & $8.32 \mathrm{E}-11$ & $\begin{array}{l}\text { AIPL1, OR4X1, CASR, OR5C1, GPR25, } \\
\text { GALR2, OR7C2, MRGPRF, CLEC7A, TREM2 }\end{array}$ & 3.68 \\
\hline GOTERM_BP_FAT & $\begin{array}{l}\text { GO:0007186 G-protein coupled receptor } \\
\text { protein signalling pathway }\end{array}$ & $6.60 \mathrm{E}-11$ & $\begin{array}{l}\text { OR4X1, CASR, OR5C1, CCL23, GPR25, } \\
\text { GALR2, OR7C2, MRGPRF, TAC4 }\end{array}$ & 4.17 \\
\hline GOTERM_BP_FAT & $\begin{array}{l}\text { GO:0007166 cell surface receptor linked } \\
\text { signal transduction }\end{array}$ & 0.001 & $\begin{array}{l}\text { OR4X1, CASR, OR5C1, CCL23, DOK5, GPR25, } \\
\text { GALR2, OR7C2, MRGPRF, CLEC7A, TAC4 }\end{array}$ & 0.08 \\
\hline GOTERM_BP_FAT & GO:0051606 detection of stimulus & 0.02 & AIPL1, CASR, CLEC7A & 13.23 \\
\hline INTERPRO & IPR017452:GPCR, rhodopsin-like superfamily & 0.009 & OR4X1, OR5C1, GPR25, GALR2, OR7C2, MRGPRF & 4.44 \\
\hline KEGG_PATHWAY & hsa04740:Olfactory transduction & 0.09 & OR4X1, OR5C1, OR7C2 & 5.31 \\
\hline GOTERM_BP_FAT & GO:0006954 inflammatory response & 0.02 & C8B, CCL23, CLEC7A, CD163 & 6.40 \\
\hline GOTERM_BP_FAT & GO:0006952 defense response & 0.02 & C8B, CCL23, MPO, CLEC7A, CD163 & 4.23 \\
\hline GOTERM_BP_FAT & GO:0006955 immune response & 0.03 & C8B, CCL23, LST1, CLEC7A, TREM2 & 3.77 \\
\hline GOTERM_BP_FAT & $\begin{array}{l}\text { GO:0006874 cellular calcium ion } \\
\text { homeostasis }\end{array}$ & 0.04 & CASR, CCL23, GALR2 & 8.53 \\
\hline GOTERM_BP_FAT & GO:0030182 neuron differentiation & 0.04 & LST1, NKX6-2, GALR2, EN2 & 4.75 \\
\hline GOTERM_CC_FAT & GO:0005886 plasma membrane & 0.02 & $\begin{array}{l}\text { CASR, OR5C1, SLC7A9, MRGPRF, CDHR5, CD163, C8B, } \\
\text { OR4X1, ADAP2, GALR2, GPR25, OR7C2, CLEC7A, TREM2 }\end{array}$ & 1.65 \\
\hline GOTERM_CC_FAT & GO:0005576 extracellular region & 0.071 & KLKBL4, C8B, CCL23, MPO, TAC4, TREM2, CSN1S1, CD163 & 2.03 \\
\hline SP_PIR_KEYW & Disulfide bond & $1.06 \mathrm{E}-12$ & $\begin{array}{l}\text { KLKBL4, OR5C1, ALPK3, SLC7A9, GALNTL1, CSN1S1, CD163, } \\
\text { C8B, OR4X1, CCL23, GALR2, OR7C2, MPO, CLEC7A, TREM2 }\end{array}$ & 2.99 \\
\hline SP_PIR_KEYW & Glycoprotein & 0.06 & $\begin{array}{l}\text { KLKBL4, CASR, OR5C1, MRGPRF, CDHR5, CD163, C8B, } \\
\text { OR4X1, GALR2, OR7C2, MPO, CLEC7A, TREM2 }\end{array}$ & 1.75 \\
\hline
\end{tabular}

The analysis was performed by DAVID Bioinformatics Resources 6.7 (http://david.abcc.ncifcrf.gov). The genes associated with annotation terms with enrichment $p<0.1$ are reported here.

these remedies, particularly for highly diluted solutions, have suffered from problems with replicability between different laboratories. It is therefore important for any results in this field to be confirmed and consolidated through further investigations by independent laboratories, using rigorous protocols and statistical evaluations. The expression microarray analysis on whole genome, as other high-throughput technologies assisted by bioinformatics, could provide a strong clue as to the mechanism of action and the biological relevance of ultra-low doses and high dilutions interactions.

This is the first comparative transcriptomics approach to investigate changes in the human neurocytes induced by a natural plant remedy, traditionally used for anxiolytic-like effects. The chief innovation of our experimental design is that it employs a wide range of doses/dilutions. This enabled us to explore changes in gene expression from low dilutions (2c or $3 \mathrm{c}$ ), where the active substances can still be expected to exert their normal pharmaceutical action, to high dilutions (9c or 30c), where the most controversial principles of high dilution pharmacology come into play. Thus, both conventional and 'alternative' pharmacological theories were evaluated and compared in the same investigation. In previous recent trials, Gelsemium s. showed anxiolytic-like effects in mouse emotional response models and appeared to work even at the high dilutions $9 \mathrm{c}$ and 30c [26,27]. Two other studies have also found that high dilutions of Gelsemium s. exert a preventive action against experimental stress (electric shock) in mice [29] and against convulsions provoked by lithium and pilocarpine in rats [5]. Other researchers have reported an anti-anxiety activity of Gelsemium s. [12] and of the alkaloids gelsemine, koumine, and gelsevirine $[14,16]$, but have not explored the effect of ultra-low doses and high dilutions/dynamizations.

To follow up on these in vivo studies, we decided to investigate the action of Gelsemium s. at the cellular and transcriptional level. We adopted a validated microarray protocol and applied it to a series of replicate experiments designed to test: a) the null hypothesis that the effect of any Gelsemium s. dilutions is similar to that of the control vehicle, b) whether any dose-dependence of the putative effects can be demonstrated. As our model system, we chose the SH-SY5Y and IMR-32 neurocyte cell lines because these have been previously employed for investigations of natural compounds [31], neurotrophic factors [32], mood stabilisers [59], and antipsychotics [33]. In our conditions, this line proved to be more responsive to Gelsemium s. than IMR-32 and was used to compare the effects of high dilutions. The cells 
were functional, as demonstrated by intracellular calcium increase following treatment with the neurotransmitter carbachol, and none of the Gelsemium s. dilutions affected their growth rate or metabolic activity.

\section{Low-dilution effects}

The most evident and statistically significant modification of cellular gene expression was induced by the lowest dilution of the medicine that we tested, namely Gelsemium s. 2c, as is to be expected with a dosedependent effect. Spectroscopic analysis of the tested samples confirmed that the starting 1c solution supplied by manufacturer contained a considerable amount of original extract compounds, and proportionate quantities were also detected in the $2 \mathrm{c}$ dilutions prepared both by the manufacturer and in our laboratory. However, dilution equal or beyond $3 \mathrm{c}$ brought the concentration of detectable compounds below the minimum sensitivity threshold of optical spectroscopy.

Although Gelsemium s. contains several different compounds [2,3], the major active alkaloid of this plant is gelsemine, which was present in a concentration of $6.5 \times 10^{-9} \mathrm{M}$ in the final incubation mixture of cells treated with Gelsemium s. 2c. This nanomolar dosage is much lower than the toxic doses that have been reported in poisoning cases [60] and in experimental evaluations of LD50 [14]. In fact, Gelsemium s. 2c at the lowest dilution (highest dose) tested in this model system did not cause cell toxicity or viability impairment. This evidence is in agreement with recent hypotheses explaining the homeopathic effects (in the range of very low doses) in the framework of hormesis, where substance which are toxic at high doses turn into therapeutic when diluted to low and ultra-low doses [61]. According to the hormetic theory, ultra-diluted drugs and nanoparticles will act as low-dose stress conditions that could possibly evoke an adaptive response process producing effects that might modulate gene expression [62-64].

The effects on gene expression observed here are specifically targeted to the regulation of certain functions, possibly linked with the plant's pharmacological activity. Of a total of 45033 transcripts, 49 were down-regulated and 7 up-regulated by the 2c dilution. This effect was quantitatively small (absolute value of fold change between 0.5 and 1.0) but statistically significant (adjusted $p<0.05)$. In general, the prevalence of down-regulation seems to indicate a tendency to reduce cell excitability, especially because several of the genes in question belong to surface receptors involved in GPCR signaling and calcium homeostasis. Moreover, this first microarray screening of the effects of Gelsemium s. on neurocytes revealed a significant down-regulation of genes for inflammatory response, olfactory transduction and neuron differentiation. Clearly, this plant species contains a variety of active chemical principles which are presumably involved in different pathways of cell regulation besides the pure neural function, as suggested by reports of possible anticancer and immunomodulating activities [17-19].

A hypothetical neurological target of Gelsemium s. has been suggested by studies showing that gelsemine stimulates the biosynthesis of allopregnanolone in the rat brain $[30,65]$, but the genes of neurosteroid enzymatic pathways were not modulated in our cell system. This apparent discrepancy may depend either on the fact that we used a cell line, whereas Venard et. al. [30,65] used slices of spinal cord and limbic system, or on the fact that they studied a post-translational level of regulation, linked to enzyme function and not to gene expression. In any case, since in our model the effects of Gelsemium $s$. were quantitatively small, as confirmed by RT-PCR results, no definite conclusions regarding the role of single genes in the action mechanism of this plant can be drawn at this stage.

These microarray findings can be regarded as a preliminary screening of the sensitivity of SH-SY5Y cellular system to Gelsemium s., while more robust conclusions about the possible role of the implicated genes will require to determine whether proteins encoded by the affected genes are similarly changed, through proteomic and phosphoproteomic approaches, and/or further studies using plant purified active compounds.

\section{Ultra-low doses and high dilutions}

The second major goal of this investigation was to study the dose-effect relationship, which is of central importance in any kind of pharmacological approach. As noted above, the Gelsemium s. 2c dilution yielded statistically significant results for 56 genes. This raised the question of whether those same genes, which appeared to be most sensitive to Gelsemium s., would also be modified by higher dilutions. Since the quantitative changes for the $3 \mathrm{c}$ and higher dilutions were quite low (Table 3 and Figure 7B), the 4 replicates were insufficient to yield statistical confidence for analysis of single transcripts. We therefore employed cluster analysis to separately describe the trends of 6 gene subsets with similar expression profiles. All 4 down-regulated clusters included genes with negative mean fold changes, though of varying magnitude. Most notably, we found two clusters ( 2 and 3 in Figure 7) that included a total of 24 genes clearly responsive to Gelsemium s. 30c, and characterized by a bell-shaped dilution-effect curve. Exploring results accurately (Table 3 ), some genes showed an interesting pattern of expression in function of Gelsemium dilution. For instance, the EN2 gene that was underexpressed in treated cells exhibited a bell-shaped curve. This tendency can be seen in other genes in the cluster analysis. Moreover, it seems that after 9c, another wave 
of expressions or no-expressions is recovered. Maybe future testing even higher dilutions, such as 100c or 200c, the bell-shaped curve could be more evident and, thus, the hypothesis of ultra-sensible genes could be checked.

For the high dilutions, due to the small changes of gene expression, the only hypothesis statistically evaluable is the global effect of Gelsemium s. dilutions on the 49 down-regulated and 7 up-regulated genes, considered as gene-sets. Using the Fisher exact test (Gelsemium $s$. dilutions vs. their respective control solutions), the null hypothesis was rejected for every dilution in the downregulated gene-set. This outcome of our microarray analysis is astounding if we consider that the $9 \mathrm{c}$ and $30 \mathrm{c}$ dilutions were obtained from MT extract by dilution factors of $10^{18}$ and $10^{60}$ respectively. Starting from a crude MT containing the active principle gelsemine at a concentration of $6.5 \times 10^{-4} \mathrm{M}$, the $9 \mathrm{c}$ dilution would theoretically contain $6.5 \times 10^{-22} \mathrm{M}$ gelsemine, corresponding to less than 1 molecule per $\mathrm{ml}$ in the final working solution; even in the case of the $5 \mathrm{c}$ dilution, where the theoretical gelsemine concentration is $6.5 \times 10^{-15} \mathrm{M}$, it can be calculated that this would correspond to $3.9 \times 10^{7}$ molecules per culture plate, i.e. about 13 molecules per seeded cell. These results suggest that neurocytes have a number of genes with extreme sensitivity to Gelsemium s. effects, even if those effects of high dilutions are quantitatively very small (decrease in expression by approximately $10 \%$ to $20 \%$ compared to the control). The physiological or pharmacological implications of this observation remain to be clarified, but the rejection of the null hypothesis furnishes a new input for the open debate on this kind of therapeutic approach.

\section{Technical issues and confounding factors}

The puzzling evidence of gene expression changes under the influence of homeopathic dilutions prompt an analysis of the possible confounding factors that might explain the effects observed. We adopted different measures to address the issue of possible experimental artifacts. To avoid dye-bias artifacts a single-channel microarray was employed. We adopted a microarray design with probes of the same probe-set located in not contiguous positions on the array, so that artifacts due to uneven hybridization would only affect a subset of probes for a probe-set. Anyhow, the absence of spatial biases in fluorescence signal was assessed by checking the coefficient of variation of the mean signal intensities of different portions of each array. The experimental set up could have introduced biases and "position effects" if handling of control and Gelsemium s. matched dilutions was not equivalent. Actually, we conducted four independent experiments in which Gelsemium s. dilutions and the corresponding vehicle controls were processed in tandem (from drug addition to RNA extraction and cDNA synthesis). In every subarray of the chip, each transcript was targeted with three separate probes, merging the fluorescence values and attributing a statistical score.

Regarding the statistical analysis, the large number of genes of the complete set causes some problems concerning the choice of "interesting" genes. The approach followed here was quite stringent and limited the number of genes considered, reducing the probability of "false positive" results, but forcing to discard some possibly interesting genes from the analysis. Moreover, the small entity of the expression changes observed with high dilutions unavoidably reduced statistical inference in the single genes, especially since multiplicity corrections were applied. The choice of analyzing the sign of the fold changes in a pool of genes, rather than the variance of a single gene, may lead to a loss of statistical information, to the advantage of greater precision in discarding the null hypothesis. Further research specifically oriented on the most responsive genes, with suitable sample sizes, could possibly overcome this limitation of the microarray approach.

\section{Physico-chemical and biological hypotheses}

Our results are in keeping with a number of experimental observations from a variety of research fields, confirming that highly diluted compounds exert statistically significant effects on biological systems [66-69]. Thus far there is no satisfactory or unifying theoretical explanation for these claims, though some have hypothesized that the dynamics of the solvent water (or water-ethanol) on a mesoscopic scale may play a part [70]. Three major models for how this happens are currently being investigated: the water clusters or clathrates, the coherent domains postulated by quantum electrodynamics, and the formation of nanoparticles from the original solute plus solvent components. It has been suggested that a major role in the formation of water clusters is played by silica released from the glass containers which are usually employed in the preparation of homeopathic drugs [71]. Silica nanostructures formed during succussion in glass and/or biosynthesized by specific plant extract tinctures may also acquire and convey epitaxial information from the remedy source materials into the higher potencies $[21,72,73]$. In our experimental model, since the verum were succussed samples, we used the succussed ethanol/water solutions as negative controls and evaluated preliminarily the variability of the negative system before assessing the biological effect of the succussed/diluted drug. Notably, in our experiments serial dilutions/succussions were performed in glass bottles, with the exception of the last step, which was developed in polystyrene tubes. Thus the hypothetical role of silicates in nanoparticle formation is pertinent, but also the contribution of polystyrene should not be excluded [74]. 
Recent evidence supports the plausibility that homeopathic Gelsemium s. in the potencies tested could contain crudely formed nanoparticles. Bel-Haaj et al. [75] demonstrated that just extended ultrasonication of plant starch can create starch nanoparticles in water. Moreover, electron microscopic evidence of nanoparticles has been obtained in several different plants prepared homeopathically [76]. Gelsemium mother tincture itself, like many other plant extracts, can biosynthesize nanoparticles of silver metal from precursor substrate [77]. Nanoparticles have unique biological and physicochemical properties, including increased catalytic reactivity, protein and DNA adsorption, bioavailability, dose-sparing, electromagnetic, and quantum effects that are different from those of bulkform materials [23]. As an example, Prakash and colleagues [78] compared in model animals the anti-anxiety effects of hypericum prepared as gold nanoparticles versus a bulk form and observed more significant effects with the nano-hypericum, even at a 10-fold lower dose. Higher cellular uptake of nano-encapsulated (poly lactide-coglycolide) Gelsemium s. than of its bulk form has been observed by Bhattacharyya et al. [79].

The hypotheses regarding the possible biological mechanisms of highly diluted/dynamized solutions (beyond Avogadro-Loschmidt limit) at the level of DNA expression variously invoke sensitivity to bioelectromagnetic information, participation of water chains in signaling, stochastic resonance, and regulation of bifurcation points of nonlinear systemic networks [64,80-83]. Based on microarray data, it has been suggested that gene regulatory networks may be regarded as dynamically 'critical' systems poised near the phase transition between order and chaos $[80,84,85]$, where extreme sensitivity to initial conditions and small perturbations is well known to occur. Chaotic regimes have been found in a number of physiological systems, including neural systems [86-88], and this would result in enhanced susceptibility to extremely low energy inputs and to small changes of regulatory factors. According to this argument, the highly diluted drug might be regarded as a solution endowed with water clusters and/or nanoparticulate structures capable of communicating some pharmacological information, through a resonance process, to biological fluids and to cell critical systems such as macromolecules, alpha-helixes, filamentous structures, receptors and DNA networks. This effect could be mediated by the participation of a dynamic intracellular water network which may be presumed to exist in living cells [89].

\section{Conclusions}

This study provides evidence that Gelsemium s. exerts a prevalently inhibitory effect on a series of neurocyte genes across a wide dose-range. The effect decreases with increasing dilutions, but whole genome expression analysis allowed to detect statistically significant changes even at the highest dilutions tested (9c and 30c). The results suggest the extreme sensitivity of human gene expression to regulation by ultra-low doses and high dilutions/dynamizations of a plant remedy and encourage further efforts in research on this field. Studies using "omic-based" approaches and systems biology should be particularly worthy at generating new hypotheses on mechanisms for the effects of highly diluted natural compounds.

\section{Additional files}

\begin{abstract}
Additional file 1: Microarray expression values of 56 transcripts in SH-SY5Y neurocytes treated with Gelsemium s. or control dilutions. Data are reported as Log2 transformed fluorescence values from four replicate microarray assays.

Additional file 2: Frequency of fold change values in a randomly chosen gene-set after Gelsemium s. treatments. A list of 49 genes was generated by randomized selection from the whole transcriptome using SPSS software (excluding the differentially expressed genes) and fold change was calculated from the difference of mean Log2 fluorescence values of Gelsemium s.-treated samples (Gnc) vs those of controls (Ctnc). Absolute fold changes less than or equal to 0.05 were considered null. Blue bars: frequencies of genes with negative fold change $(<-0.05)$; grey bars: frequency of unaffected genes (from -0.05 to 0.05 ); pink bars: frequencies of genes with positive fold change $(>0.05)$. For these randomly selected genes, Fisher exact test is not significant in any dilution.
\end{abstract}

\section{Competing interests}

The authors declare that they have no competing interests.

\section{Authors' contributions}

PB conceived the experiments, MM, DO and MC designed and performed the experiments, $\mathrm{PT}, \mathrm{MB}, \mathrm{MM}$, and $\mathrm{DO}$ analyzed the data, MM and PB wrote the paper. All authors read and approved the final manuscript.

\section{Acknowledgments}

This work was supported by grants from Boiron Laboratories to the University of Verona and from the Italian Research Ministry. We thank Prof. Ubaldo Armato, Dr. Ilaria Pierpaola Dal Pra for SH-SY5Y cells and their helpful advice and Dr. Clara Bonafini for her collaboration in cell cultures.

\section{Author details}

${ }^{1}$ Department of Pathology and Diagnostics, University of Verona, Strada Le Grazie 8, Verona 37134, Italy. ${ }^{2}$ Department of Statistical Sciences, University of Bologna, Via delle Belle Arti 41, Bologna 40126, Italy. ${ }^{3}$ Department of Biotechnology, University of Verona, Strada Le Grazie 15, Verona 37134, Italy.

Received: 30 May 2013 Accepted: 13 March 2014

Published: 19 March 2014

\section{References}

1. Schun Y, Cordell GA: Cytotoxic steroids of Gelsemium sempervirens. J Nat Prod 1987, 50:195-198.

2. Dutt V, Thakur S, Dhar VJ, Sharma A: The genus Gelsemium: an update. Pharmacogn Rev 2010, 4:185-194.

3. Jin GL, Su YP, Liu M, Xu Y, Yang J, Liao KJ, Yu CX: Medicinal plants of the genus Gelsemium (Gelsemiaceae, Gentianales)-a review of their phytochemistry, pharmacology, toxicology and traditional use. J Ethnopharmacol 2014. doi:10.1016/j.jep.2014.01.003.

4. Valnet J: Phytothérapie. Paris: Maloine; 1992.

5. Peredery O, Persinger MA: Herbal treatment following post-seizure induction in rat by lithium pilocarpine: Scutellaria lateriflora (Skullcap), Gelsemium sempervirens (Gelsemium) and Datura stramonium (Jimson 
Weed) may prevent development of spontaneous seizures. Phytother Res 2004, 18:700-705.

6. Boericke W: Materia Medica with Repertory. Philadelphia: Boericke \& Tafel, Inc; 1927.

7. Binsard AM, Guillemain J, Platel A, Savini EC, Tetau M: Etude psycho-pharmacologique de dilutions homéopathiques de Gelsemium et d'Ignatia. Ann Homeop Fr 1980, 22:35-50.

8. Guillemain J, Rousseau A, Dorfman P, Tetau M: Recherche en psychopharmacologie. Cah Biother 1989, 103:53-66.

9. Guermonprez M: Homéopathie, Principles - Clinique - Techniques. Paris: CEDH; 2006

10. Bellavite P, Magnani P, Marzotto M, Conforti A: Assays of homeopathic remedies in rodent behavioural and psychopathological models. Homeopathy 2009, 98:208-227.

11. Gahlot K, Abid M, Sharma A: Pharmacological evaluation of Gelsemium sempervirens roots for CNS depressant activity. Int J Pharm Tech Res 2012, 3:693-697.

12. Dutt V, Dhar VJ, Sharma A: Antianxiety activity of Gelsemium sempervirens. Pharm Biol 2010, 48:1091-1096.

13. Liu M, Shen J, Liu H, Xu Y, Su YP, Yang J, Yu CX: Gelsenicine from Gelsemium elegans attenuates neuropathic and inflammatory pain in mice. Biol Pharm Bull 2011, 34:1877-1880.

14. Liu M, Huang HH, Yang J, Su YP, Lin HW, Lin LQ, Liao WJ, Yu CX: The active alkaloids of Gelsemium elegans Benth. are potent anxiolytics. Psychopharmacology (Berl) 2013, 225:839-851.

15. Zhang JY, Gong N, Huang JL, Guo LC, Wang YX: Gelsemine, a principal alkaloid from Gelsemium sempervirens Ait., exhibits potent and specific antinociception in chronic pain by acting at spinal alpha3 glycine receptors. Pain 2013, 154:2452-2462.

16. Meyer L, Boujedaini N, Patte-Mensah C, Mensah-Nyagan AG: Pharmacological effect of gelsemine on anxiety-like behavior in rat. Behav Brain Res 2013, 253:90-94.

17. Bhattacharyya SS, Mandal SK, Biswas R, Paul S, Pathak S, Boujedaini N, Belon P, Khuda-Bukhsh AR: In vitro studies demonstrate anticancer activity of an alkaloid of the plant Gelsemium sempervirens. Exp Biol Med (Maywood) 2008, 233:1591-1601

18. Zhao QC, Hua W, Zhang L, Guo T, Zhao MH, Yan M, Shi GB, Wu L: Antitumor activity of two gelsemine metabolites in rat liver microsomes. J Asian Nat Prod Res 2010, 12:731-739.

19. Rammal H, Soulimani R: Effects of high doses of Gelsemium sempervirens L. on GABA receptor and on the cellular and humoral immunity in mice. $J$ Med Med Sci 2010, 1:40-44.

20. Xu YK, Liao SG, Na Z, Hu HB, Li Y, Luo HR: Gelsemium alkaloids, immunosuppressive agents from Gelsemium elegans. Fitoterapia 2012, 83:1120-1124.

21. Roy R, Tiller W, Bell IR, Hoover MR: The structure of liquid water. Novel insights from materials research; potential relevance to homeopathy. Mat Res Innovat 2005, 9:98-103.

22. Yinnon TA, Yinnon CA: Electric dipole aggregates in very diluted polar liquids: theory and experimental evidence. Int J Mod Phys B 2011, 25:3707-3743

23. Bell IR, Koithan M: A model for homeopathic remedy effects: low dose nanoparticles, allostatic cross-adaptation, and time-dependent sensitization in a complex adaptive system. BMC Complement Altern Med 2012, 12:191.

24. Endler $P$, Thieves $K$, Reich $C$, Matthiessen $P$, Bonamin $L$, Scherr $C$, Baumgartner $\mathrm{S}$ : Repetitions of fundamental research models for homeopathically prepared dilutions beyond 10(-23): a bibliometric study. Homeopathy 2010, 99:25-36.

25. Stock-Schroer B, Albrecht H, Betti L, Dobos G, Endler C, Linde K, Lüdtke R, Musial F, van Wijk R, Witt C, Baumgartner S: Reporting experiments in homeopathic basic research-description of the checklist development. Evid Based Complement Alternat Med 2011, 2011:639260.

26. Magnani P, Conforti A, Zanolin E, Marzotto M, Bellavite P: Dose-effect study of Gelsemium sempervirens in high dilutions on anxiety-related responses in mice. Psychopharmacology (Berl) 2010, 210:533-545.

27. Bellavite P, Conforti A, Marzotto M, Magnani P, Cristofoletti M, Olioso D, Zanolin ME: Testing homeopathy in mouse emotional response models: pooled data analysis of two series of studies. Evid Based Complement Alternat Med 2012, 2012:954374.

28. Sukul NC, Bala SK, Bhattacharyya B: Prolonged cataleptogenic effects of potentized homoeopathic drugs. Psychopharmacology (Berl) 1986, 89:338-339
29. Bousta D, Soulimani R, Jarmouni I, Belon P, Falla J, Foment N, Younos C: Neurotropic, immunological and gastric effects of low doses of Atropa belladonna L., Gelsemium sempervirens L. and Poumon histamine in stressed mice. J Ethnopharmacol 2001, 74:205-215.

30. Venard C, Boujedaini N, Mensah-Nyagan AG, Patte-Mensah C: Comparative analysis of gelsemine and Gelsemium sempervirens activity on neurosteroid allopregnanolone formation in the spinal cord and limbic system. Evid Based Complement Alternat Med 2011:407617. doi:10.1093/ecam/nep083.

31. Seo JJ, Lee SH, Lee YS, Kwon BM, Ma Y, Hwang BY, Hong JT, Oh KW: Anxiolytic-like effects of obovatol isolated from Magnolia obovata: involvement of GABA/benzodiazepine receptors complex. Prog Neuropsychopharmacol Biol Psychiatry 2007, 31:1363-1369.

32. Donnici L, Tiraboschi E, Tardito D, Musazzi L, Racagni G, Popoli M: Time-dependent biphasic modulation of human BDNF by antidepressants in neuroblastoma cells. BMC Neurosci 2008, 9:61.

33. Park SW, Seo MK, Cho HY, Lee JG, Lee BJ, Seol W, Kim YH: Differential effects of amisulpride and haloperidol on dopamine D2 receptor-mediated signaling in SH-SY5Y cells. Neuropharmacology 2011, 61:761-769.

34. Fisher P: What is homeopathy? An introduction. Front Biosci (Elite Ed) 2012, 4:1669-1682.

35. Anonymous: Pharmacopée Homéopathique Française - X édition. Saint-Denis Cedex (FR): Agence Française de Sécurité Sanitaire de Produits de Santé; 2002.

36. Kohl RL, Perez-Polo JR, Quay WB: Effect of methionine, glycine and serine on serine hydroxymethyltransferase activity in rat glioma and human neuroblastoma cells. J Neurosci Res 1980, 5:271-280.

37. Chakravarthy B, Gaudet C, Menard M, Atkinson T, Brown L, Laferla FM, Armato $\mathrm{U}$, Whitfield J: Amyloid-beta peptides stimulate the expression of the p75(NTR) neurotrophin receptor in SHSY5Y human neuroblastoma cells and AD transgenic mice. J Alzheimers Dis 2010, 19:915-925.

38. Ishiyama $M$, Tominaga $H$, Shiga $M$, Sasamoto $K$, Ohkura $Y$, Ueno $K$ : A combined assay of cell viability and in vitro cytotoxicity with a highly water-soluble tetrazolium salt, neutral red and crystal violet. Biol Pharm Bull 1996, 19:1518-1520.

39. Irizarry RA, Hobbs B, Collin F, Beazer-Barclay YD, Antonellis KJ, Scherf U, Speed TP: Exploration, normalization, and summaries of high density oligonucleotide array probe level data. Biostatistics 2003, 4:249-264.

40. Bolstad BM, Irizarry RA, Astrand M, Speed TP: A comparison of normalization methods for high density oligonucleotide array data based on variance and bias. Bioinformatics 2003, 19:185-193.

41. Edgar R, Domrachev M, Lash AE: Gene Expression Omnibus: NCBI gene expression and hybridization array data repository. Nucleic Acids Res 2002, 30:207-210.

42. Smyth GK, Michaud J, Scott HS: Use of within-array replicate spots for assessing differential expression in microarray experiments. Bioinformatics 2005, 21:2067-2075.

43. Benjamini $Y$, Hochberg $Y$ : Controlling the false discovery rate: a practical and powerful approach to multiple testing. J Royal Statistical Soc Series B (Methodological) 1995, 57:289-300.

44. Saeed Al, Bhagabati NK, Braisted JC, Liang W, Sharov V, Howe EA, Li J, Thiagarajan M, White JA, Quackenbush J: TM4 microarray software suite. Methods Enzymol 2006, 411:134-193.

45. Brock G, Datta S, Pihur V, Datta S: clValid: an R package for cluster validation. J Stat Softw 2008, 25:1-22.

46. Huang dW, Sherman BT, Lempicki RA: Systematic and integrative analysis of large gene lists using DAVID bioinformatics resources. Nat Protoc 2009, 4:44-57.

47. Franco MI, Turin L, Mershin A, Skoulakis EM: Molecular vibration-sensing component in Drosophila melanogaster olfaction. Proc Natl Acad Sci USA 2011, 108:3797-3802.

48. Tran AH, Berger A, Wu GE, Kee BL, Paige CJ: Early B-cell factor regulates the expression of Hemokinin-1 in the olfactory epithelium and differentiating $B$ lymphocytes. J Neuroimmunol 2011, 232:41-50.

49. Cunin P, Caillon A, Corvaisier M, Garo E, Scotet M, Blanchard S, Delneste Y, Jeannin $P$ : The tachykinins substance $P$ and hemokinin-1 favor the generation of human memory Th17 cells by inducing IL-1beta, IL-23, and TNF-like 1A expression by monocytes. J Immunol 2011, 186:4175-4182.

50. Madaan V, Wilson DR: Neuropeptides: relevance in treatment of depression and anxiety disorders. Drug News Perspect 2009, 22:319-324.

51. Alherbish A, Charrois TL, Ackman ML, Tsuyuki RT, Ezekowitz JA: The prevalence of natural health product use in patients with acute cardiovascular disease. PLOS ONE 2011, 6:e19623. 
52. Barbancey J: Pratique Homéopathique en psycho-pathologie, Tome II. Paris: Editions Similia; 1987.

53. Danno K, Colas A, Masson JL, Bordet MF: Homeopathic treatment of migraine in children: results of a prospective, multicenter, observational study. J Altern Complement Med 2012, 19:119-123.

54. Paris A, Gonnet N, Chaussard C, Belon P, Rocourt F, Saragaglia D, Cracowski JL: Effect of homeopathy on analgesic intake following knee ligament reconstruction: a phase III monocentre randomized placebo controlled study. Br J Clin Pharmacol 2008, 65:180-187.

55. Bellavite $\mathrm{P}$, Conforti A, Piasere V, Ortolani R: Immunology and homeopathy. 1. Historical background. eCAM 2005, 2:441-452.

56. Shang A, Huwiler-Müntener K, Nartey L, Jüni $P$, Dörig S, Sterne JAC, Pewsner D, Egger M: Are the clinical effects of homoeopathy placebo effects? Comparative study of placebo-controlled trials of homoeopathy and allopathy. Lancet 2005, 366:726-732.

57. Jonas WB, Kaptchuk TJ, Linde K: A critical overview of homeopathy. Ann Intern Med 2003, 138:393-399.

58. Calabrese EJ, Jonas WB: Evaluating homeopathic drugs within a biomedical framework. Hum Exp Toxicol 2010, 29:545-549.

59. Plant KE, Anderson E, Simecek N, Brown R, Forster S, Spinks J, Toms N, Gibson GG, Lyon J, Plant N: The neuroprotective action of the mood stabilizing drugs lithium chloride and sodium valproate is mediated through the up-regulation of the homeodomain protein Six1. Toxicol Appl Pharmacol 2009, 235:124-134.

60. Lai CK, Chan YW: Confirmation of Gelsemium poisoning by targeted analysis of toxic Gelsemium alkaloids in urine. J Anal Toxicol 2009, 33:56-61.

61. Calabrese EJ, Jonas WB: Homeopathy: clarifying its relationship to hormesis. Hum Exp Toxicol 2010, 29:531-536.

62. lavicoli I, Calabrese EJ, Nascarella MA: Exposure to nanoparticles and hormesis. Dose Response 2010, 8:501-517.

63. Van Wijk R, Wiegant FA: Postconditioning hormesis and the homeopathic Similia principle: molecular aspects. Hum Exp Toxicol 2010, 29:561-565.

64. Bell IR, Schwartz GE: Adaptive network nanomedicine: an integrated model for homeopathic medicine. Front Biosci (Schol Ed) 2013, 5:685-708.

65. Venard C, Boujedaini N, Belon P, Mensah-Nyagan AG, Patte-Mensah C: Regulation of neurosteroid allopregnanolone biosynthesis in the rat spinal cord by glycine and the alkaloidal analogs strychnine and gelsemine. Neuroscience 2008, 153:154-161.

66. Bellavite P, Conforti A, Pontarollo F, Ortolani R: Immunology and homeopathy. 2. Cells of the immune system and inflammation. eCAM 2006, 3:13-24.

67. Witt CM, Bluth M, Albrecht H, Weisshuhn TE, Baumgartner S, Willich SN: The in vitro evidence for an effect of high homeopathic potencies-a systematic review of the literature. Complement Ther Med 2007, 15:128-138.

68. Sainte-Laudy J, Belon P: Inhibition of basophil activation by histamine: a sensitive and reproducible model for the study of the biological activity of high dilutions. Homeopathy 2009, 98:186-197.

69. Majewsky V, Arlt S, Shah D, Scherr C, Jager T, Betti L, Trebbi G, Bonamin L, Klocke P, Baumgartner S: Use of homeopathic preparations in experimental studies with healthy plants. Homeopathy 2009, 98:228-243.

70. Bellavite P, Marzotto M, Olioso D, Moratti E, Conforti A: High-dilution effects revisited. 1. Physicochemical aspects. Homeopathy 2014, 103:4-21.

71. Anick DJ, Ives JA: The silica hypothesis for homeopathy: physical chemistry. Homeopathy 2007, 96:189-195.

72. Chikramane PS, Suresh AK, Bellare JR, Kane SG: Extreme homeopathic dilutions retain starting materials: A nanoparticulate perspective. Homeopathy 2010, 99:231-242.

73. Relaix S, Leheny RL, Reven L, Sutton M: Memory effect in composites of liquid crystal and silica aerosil. Phys Rev E Stat Nonlin Soft Matter Phys 2011, 84:061705.

74. Baier G, Costa C, Zeller A, Baumann D, Sayer C, Araujo PH, Mailänder V, Musyanovych A, Landfester K: BSA adsorption on differently charged polystyrene nanoparticles using isothermal titration calorimetry and the influence on cellular uptake. Macromol Biosci 2011, 11:628-638.

75. Bel HS, Magnin A, Petrier C, Boufi S: Starch nanoparticles formation via high power ultrasonication. Carbohydr Polym 2013, 92:1625-1632.

76. Upadhyay RP, Nayak C: Homeopathy emerging as nano medicine. Int J High Dilution Res 2011, 10:299-310.

77. Das S, Das J, Samadder A, Bhattacharyya SS, Das D, Khuda-Bukhsh AR: Biosynthesized silver nanoparticles by ethanolic extracts of Phytolacca decandra, Gelsemium sempervirens, Hydrastis canadensis and Thuja occidentalis induce differential cytotoxicity through G2/M arrest in A375 cells. Colloids Surf B Biointerfaces 2013, 101:325-336.

78. Prakash DJ, Arulkumar S, Sabesan M: Effect of nanohypericum (Hypericum perforatum gold nanoparticles) treatment on restraint stressinduced behavioral and biochemical alteration in male albino mice. Pharmacognosy Res 2010, 2:330-334.

79. Bhattacharyya SS, Paul S, Khuda-Bukhsh AR: Encapsulated plant extract (Gelsemium sempervirens) poly (lactide-co-glycolide) nanoparticles enhance cellular uptake and increase bioactivity in vitro. Exp Biol Med (Maywood) 2010, 235:678-688.

80. Schwartz GE, Russek LG, Bell IR, Riley D: Plausibility of homeopathy and conventional chemical therapy: the systemic memory resonance hypothesis. Med Hypotheses 2000, 54:634-637.

81. Bellavite P: Complexity science and homeopathy. A synthetic overview. Homeopathy 2003, 92:203-212.

82. Bellavite $P$, Olioso D, Marzotto M, Moratti E, Conforti A: A dynamic network model of the similia principle. Complement Ther Med 2013, 21:750-761.

83. Bellavite P, Marzotto M, Olioso D, Moratti E, Conforti A: High-dilution effects revisited. 2. Pharmacodynamic mechanisms. Homeopathy 2014 103:22-43.

84. Ramo P, Kesseli J, Yli-Harja O: Perturbation avalanches and criticality in gene regulatory networks. J Theor Biol 2006, 242:164-170.

85. Likhoshvai VA, Fadeev SI, Kogai W, Khlebodarova TM: On the chaos in gene networks. J Bioinform Comput Biol 2013, 11:1340009.

86. Morita K, Tsumoto K, Aihara K: Possible effects of depolarizing GABAA conductance on the neuronal input-output relationship: a modeling study. J Neurophysio/ 2005, 93:3504-3523.

87. Gupta K, Singh HP, Biswal B, Ramaswamy R: Adaptive targeting of chaotic response in periodically stimulated neural systems. Chaos 2006 16:023116.

88. Qi Y, Watts AL, Kim JW, Robinson PA: Firing patterns in a conductance-based neuron model: bifurcation, phase diagram, and chaos. Biol Cybern 2013, 107:15-24.

89. Szolnoki Z: A dynamically changing intracellular water network serves as a universal regulator of the cell: the water-governed cycle. Biochem Biophys Res Commun 2007, 357:331-334.

doi:10.1186/1472-6882-14-104

Cite this article as: Marzotto et al:: Extreme sensitivity of gene expression in human SH-SY5Y neurocytes to ultra-low doses of Gelsemium sempervirens. BMC Complementary and Alternative Medicine 2014 14:104.

\section{Submit your next manuscript to BioMed Central and take full advantage of:}

- Convenient online submission

- Thorough peer review

- No space constraints or color figure charges

- Immediate publication on acceptance

- Inclusion in PubMed, CAS, Scopus and Google Scholar

- Research which is freely available for redistribution 